\title{
In memoriam Douglas N. Walton: the influence of Doug Walton on Al and law
}

\author{
Katie Atkinson ${ }^{1}$ - Trevor Bench-Capon ${ }^{1}$ - Floris Bex ${ }^{2,3}$. Thomas F. Gordon ${ }^{4}$. \\ Henry Prakken $^{2,5} \cdot$ Giovanni Sartor $^{6,7} \cdot$ Bart Verheij $^{8}$
}

Published online: 16 June 2020

(c) The Author(s) 2020

\begin{abstract}
Doug Walton, who died in January 2020, was a prolific author whose work in informal logic and argumentation had a profound influence on Artificial Intelligence, including Artificial Intelligence and Law. He was also very interested in interdisciplinary work, and a frequent and generous collaborator. In this paper seven leading researchers in AI and Law, all past programme chairs of the International Conference on $\mathrm{AI}$ and Law who have worked with him, describe his influence on their work.
\end{abstract}

Keywords Argument schemes $\cdot$ Dialogue types $\cdot$ Legal reasoning

\section{Introduction}

On January 3, 2020, we lost a good friend and colleague, Douglas Walton. He was 77 and is survived by his wife, Karen.

Doug served for many years as a member of the editorial board of this journal. He was one of the leading experts in the field of argumentation and highly prolific.

Trevor Bench-Capon

tbc@csc.liv.ac.uk

Thomas F. Gordon

http://www.tfgordon.de

1 Department of Computer Science, University of Liverpool, Liverpool, UK

2 Department of Information and Computing Sciences, Utrecht University, Utrecht, Netherlands

3 Institute for Law, Technology and Society, Tilburg University, Tilburg, Netherlands

$4 \quad$ Falkensee, Germany

5 Faculty of Law, University of Groningen, Groningen, Netherlands

6 Faculty of Law, European University Institute, San Domenico di Fiesole, Italy

7 Department of Legal Studies, University of Bologna, Bologna, Italy

8 Department of Artificial Intelligence, Bernoulli Institute of Mathematics, Computer Science and Artificial Intelligence, University of Groningen, Groningen, Netherlands 
He authored or co-authored more than 50 books and published more than 400 peer reviewed journal articles and conference papers. And his work was not only voluminous but also highly influential, as attested by his high citation indexes, one of the highest in our community.

Doug earned his Ph.D. in philosophy at the University of Toronto, Canada, in 1972. Before completing his Ph.D. he was awarded a professorship in the philosophy department at the University of Winnipeg, starting in 1969. He became a full professor there in 1982 and carried on in this capacity until his retirement in 2008. But research and writing remained Doug's passion and he gave no thought to the idea of actually retiring. He moved to the University of Windsor, Canada, where he held the Assumption Chair of Argumentation Studies until 2014, and then continued on at Windsor as a Distinguished Research Fellow of the Centre for Research in Reasoning, Argumentation, and Rhetoric (CRRAR) until his death.

During his long career he travelled extensively, including several longer visits as a fellow or visiting professor, at the Institute for Advanced Study in the Humanities and Social Sciences in the Netherlands (1987-1988 and 1989-1990), the Oregon Humanities Center (1997), Northwestern University (1999), the University of Arizona (2001), the University of Lugano (2007) and the Department of Law at the European University Institute, Florence (2011).

One of the hallmark's of Doug's career was his enthusiasm for interdisciplinary research, in particular in collaboration with computer scientists and lawyers working in the field of Artificial Intelligence and Law as well as, somewhat later, Computational Models of Argument. This collaboration began in the late 1990s, presumably as a result of his participation at the first Formal and Applied Practical Reasoning (FAPR) conference (Gabbay and Ohlbach 1996), which was held in Bonn, Germany, in 1996. The FAPR conference brought together researchers working on practical reasoning and other forms of argument from both philosophy and artificial intelligence. Doug was already 56 at the time and well established in philosophy as a leading expert in the field of argumentation. At this stage in his life and career he had no need to take on the challenges of entering a new, if related, field, especially a highly technical one such as artificial intelligence. But he not only persisted, overcoming challenges, but succeeded in making a large impact, significantly influencing the work of several of the leading researchers in these fields .

Of his over 50 books on argumentation, several of them were directly relevant for the field of Artificial Intelligence and Law, including Legal Argumentation and Evidence (Walton 2002), Argumentation Methods for Artificial Intelligence and Law (Walton 2005), Character Evidence, An Abductive Theory (Walton 2006a), Witness Testimony Evidence: Argumentation, Artificial Intelligence and Law (Walton 2008), Burden of Proof, Presumption and Argumentation (Walton 2014), Argument Evaluation and Evidence (Walton 2014), and the Handbook of Legal Reasoning and Argumentation (Bongiovanni et al. 2018, co-editor). Doug also published fourteen papers in the Artificial Intelligence and Law journal.

But Doug is probably best known for his original, ground-breaking work on the topics of argumentation schemes and dialogue types, as expressed for example in his books Commitment in Dialogue (Walton and Krabbe 1995, with Erik Krabbe), Argumentation Schemes for Presumptive Reasoning (Walton 1996), Argumentation 
Schemes (Walton et al. 2008, with Chris Reed and Fabrizio Macagno), The New Dialectic (Walton 1998b) and Dialog Theory for Critical Argumentation (Walton 2007). His work on argumentation schemes and dialog types is summarized in the next section of this article. And for a good overview of his perspective on argumentation, his textbook Fundamentals of Critical Argumentation (Walton 2006b) is highly recommended.

This paper commemorates Doug Walton's impact on the field of Artificial Intelligence Law, with contributions from a number of people who have worked with him, explaining how Doug's work has influenced them and, in return, how work in the field of AI and Law has influenced Doug's further work on argumentation.

We will always remember Doug fondly. He will be sorely missed.

\section{Selected overview of Walton's work}

Doug was, of course, not a computer scientist but a philosopher and an informal logician. Although he collaborated with computer scientists and published in computer science venues, his work is very much in his own tradition. None the less several aspects of his work, although motivated by concerns from his own discipline, proved inspirational to computer scientists. Two topics in particular have had a wide ranging and lasting influence. Both addressed problems that computer scientists were struggling with when they discovered his work. His work on dialogue types in Walton and Krabbe (1995) and Walton (1998b) helped to solve problems in the development of inter-agent communications, and his work on argumentation schemes (Walton 1996; Walton et al. 2008) was taken up at a time when the interest of Artificial Intelligence had been turned towards argumentation by Dung's seminal paper (Dung 1995). Dung's theory of abstract argumentation needed to be complemented by a way of doing structured argumentation, and one way of doing this was provided by argumentation schemes.

In the remainder of this section we will summarise these two important contributions.

\subsection{Dialogue types}

One aspect of Doug's work which has had a considerable impact on Computer Science is his notion of dialogue types. This idea was introduced in Walton (1989), developed and organised in joint work with Erik Krabbe, Walton and Krabbe (1995), and further expounded in Walton (1998b). The impact of this work was heightened by the context in which it was introduced.

In the mid-90s multi-agent systems were very much a hot topic of research (Sycara 1998). The basic idea was that systems could be realised as groups of communicating agents and

Implementations of systems based on distributed agent architectures require an agent communications language that has a clearly defined semantics. Without one, neither agents nor developers can be sure what another agent's commit- 
ment to perform a task means (to name just one speech act). (Smith and Cohen 1996).

As that quote suggests, a central source of inspiration was John Searle's Speech Acts (Searle 1969). The underlying idea here was that people communicate through performative utterances, utterances intended to perform actions such as asking and telling, and that these could be defined in terms of preconditions (sometimes called felicity conditions) for their use, and the post-conditions that result from their use. Thus we saw the development of several agent communication languages intended to provide agents with a repertoire of speech acts, the best known of which was KQML (Finin et al. 1994). A semantics for KQML was given in Labrou and Finin (1994). A typical example from KQML is $\operatorname{tell}(A, B, X)$, where A tells B that X.

\section{$\operatorname{tell}(\mathbf{A}, \mathbf{B}, \mathbf{X})$}

1. Preconditions for $\mathrm{A}$ : $\operatorname{bel}(\mathrm{A}, \mathrm{X})$ and $\operatorname{know}(\mathrm{A}, \operatorname{want}(\mathrm{B}, \operatorname{know}(\mathrm{B}, \operatorname{bel}(\mathrm{A}, \mathrm{X}))))$

2. Preconditions for $B$ : intend $(B, \operatorname{know}(B, \operatorname{beI}(A, X)))$

3. Postcondition for $\mathrm{A}: \operatorname{know}(\mathrm{A}, \operatorname{know}(\mathrm{B}, \operatorname{bel}(\mathrm{A}, \mathrm{X})))$

4. Postcondition for $\mathrm{B}: \operatorname{know}(\mathrm{B}, \operatorname{bel}(\mathrm{A}, \mathrm{X}))$

5. Completion: $\operatorname{know}(\mathrm{B}, \operatorname{bel}(\mathrm{A}, \mathrm{X}))$

Two features here are problematic: first that there is much appeal to internal states of the agent (believe, know, want, intend etc.), some of which are nested. Some of them cannot possibly be determined by the agent: for example $\mathrm{A}$ is required to know that $\mathrm{B}$ wants to know. These private semantics are unverifiable, and thus it is not possible to know whether the act can be performed. Partly as a result there are sincerity conditions built in to the speech acts: one cannot lie using the KQML tell. This might be possible in a closed system where all agents are known to be co-operative, but cannot easily be extended to open systems where there is always a danger of encountering malicious agents. The alternative is a semantics based not on mental states, but on social commitments (Singh 2000).

The second problem is that the definition gives a very restricted view of tell, whereas in practice the speech act is rather flexible, capable of different uses in different contexts. For example, I can tell people things that I know they do not want to know, and (since sincerity conditions do not apply in the real world), I will have no idea whether they will believe me or not.

Both of these problems are addressed by Doug's notion of dialogue types. As the title of Walton and Krabbe (1995), Commitment in Dialogue, indicates, the central idea is that agents enter into public commitments when engaged in dialogue. An agent who asserts a proposition is committed to its truth for the purposes of that dialogue, irrespective of whether the agent really believes it. These public commitments can then form the basis of preconditions for the various speech acts, without the need to speculate on mental states. In this way both participants can be observed to be obeying the protocols. The notion of commitment was already familiar from dialogue games such as Mackenzie's DC (Mackenzie 1979) and, in AI and Law, Tom Gordon's Pleadings Game (Gordon 1994), but Doug's account put the idea on firm philosophical foundations. 
The idea of different dialogue types enabled the speech acts to be considered in a context, so that the meaning could be understood in the context in which it was performed, thus allowing for the essential pragmatic aspects to be captured as well as the semantic aspects. This idea was recognised in the agent community in the conversation classes of COOL (Barbuceanu and Fox 1995), whereby specific tasks were defined as a set of speech acts specific to that task. This made the speech acts rather ad hoc, peculiar to quite specific tasks. In Bench-Capon (1998b) three different tasks in which tell might be used are specified, with the conditions specified to capture the pragmatic differences between the tasks. But whereas KQML was too general, defining the speech acts relative to single tasks was too specific. The notion of dialogue classes in Walton and Krabbe (1995) offered a sensible middle way, and one soundly based on philosophy and informal logic.

The basic tenet of Walton and Krabbe (1995) is that

propositional commitments depend on a context of dialogue. There are many different normative models of a dialogue, each of which has its own distinctive goals and rules. Accordingly it is possible to distinguish several important characteristic types of dialogue. Each type of dialogue has different kinds of rules for the management of commitments.

Six main dialogue types were identified in Walton and Krabbe (1995): persuasion, negotiation, inquiry, deliberation, information seeking and eristic. Mixed dialogues were also possible. The possibility of shifting from one dialogue type to another needs to be recognised: failing to notice such a shift so that the participants are unaware of the type of the dialogue in which they are engaged will lead to misunderstandings.

Dialogue types can be defined by specifying:

- The initial situation;

- The overall (collective) goal;

- The individual aims of the participants (which may differ or even conflict),

A summary of these defining characteristics for the six dialogue types is shown in Table 1. For each of these dialogue types it is possible to identify a set of speech acts, enabling the dialogue type to be realised in an agent system. Examples are: Prakken (2006) (persuasion), Wooldridge and Parsons (2000) (negotiation), Black and Hunter (2009) (inquiry) and Atkinson et al. (2013b) (deliberation and persuasion). Apart from the eristic type, there are examples for all the other types. These six types, however, are not intended to be exhaustive and exploration of additional types has proved fruitful: for example examination dialogues (Dunne et al. 2005) and adjudication dialogues (Prakken 2008).

Doug's work on dialogue types in an excellent illustration of the importance of interdisciplinary perspectives: work produced to satisfy concerns arising from informal logic proved immensely useful in solving problems arising in inter-agent communication, notably the avoidance of private semantics and the incorporation of 


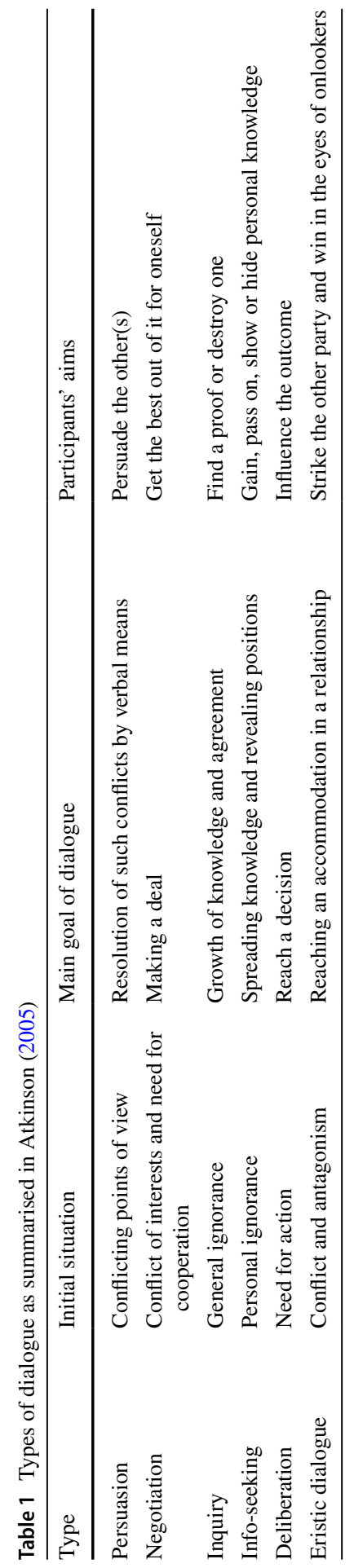


context and the pragmatic considerations arising from context in the specification of speech acts for agents.

\subsection{Argumentation schemes}

Argumentation schemes have a long history, as set out in Macagno et al. (2017). Classical versions of argumentation schemes can be found in Aristotle and Cicero. Moving on to the Middle Ages we have Boethius and Abelard. Moving on to modern times, schemes were used by Perelman and Olbrechts-Tyteca (1969), Toulmin (1958) and the Pragma-Dialectics school (van Eemeren and Grootendorst 2016). That of Toulmin had a particular impact on AI and Law (e.g. Lutomski 1989; Marshall 1989; Bench-Capon 1998a). Doug produced a distinctive account of argumentation schemes in Walton (1996) and Walton et al. (2008). It is on Doug's understanding of argumentation schemes that we will focus in this paper.

Argumentation schemes are contextual forms of argument, where the conclusion of the argument is made more plausible or persuasive if the premises of the argument are believed or accepted to be true. Schemes come with a set of critical questions suggesting ways to make other arguments which can undermine or attack the argument. Using schemes, multiple arguments pro and con a claim can be constructed, which may need to be balanced to reach a decision about whether or not to accept the claim. In Doug's own words:

Several distinct forms of argument ...are not deductive or inductive in nature. These arguments are presumptive and defeasible ...Each of the forms of argument described in this chapter is used as a presumptive argument in a dialogue that carries a weight of plausibility. If the respondent accepts the premises, then that gives him a good reason to also accept the conclusion. But it does not mean that the respondent should accept the conclusion uncritically. Matching each form of argument is a set of appropriate critical questions to ask. In a given case, there may be a balance of considerations to take into account. There may be some arguments in favour of the conclusion and some against it. These forms of argument are called argumentation schemes, and they represent many common types of argumentation that are familiar in everyday conversations. They need to be evaluated in the context of dialogue. They are used to shift a burden of proof to one side or the other in a dialogue and need to be evaluated differently at different stages of a dialogue. ...(Walton 2006b, p. 84)

Here is Doug's standard example of an argumentation scheme (Walton 2006b, pp. 87-88), for arguments from expert witness testimony, illustrating the three parts of schemes (premises, conclusion and critical questions):

Major premise Source $E$ is an expert in the subject domain $D$ containing proposition $A$.

Minor premise $E$ asserts that proposition $A$ is true.

Conclusion A may be plausibly be taken to be true. 
The critical questions of the expert witness testimony scheme are:

Expertise question How credible is $E$ as an expert source?

Field question Is $E$ an expert in the field that $A$ is in?

Opinion question What $\operatorname{did} E$ assert that implies $A$ ?

Trustworthiness question Is $E$ personally reliable as a source?

Consistency question Is A consistent with what other experts assert?

Backup evidence question Is E's assertion based on evidence?

Now we can see why schemes are contextual, unlike the inference rules of some axiomatization of classical logic. The premises, conclusion and critical questions of argumentation schemes are not entirely abstract, but make use of predicates from some domain of discourse, such as, in this example, 'expert', 'credible', 'field', and 'reliable'. By they are also not entirely concrete. The premises, conclusion and critical questions of a scheme have schema variables ( $E, D$ and $A$ in this example) which must be instantiated with constants denoting individuals when applying the scheme to construct an argument.

So far we have only discussed the form and the parts of argumentation schemes. Let us now turn to their purposes and how they are intended to be used in dialogues. They have multiple uses. Their first use, the one Doug tends to emphasise most, is for critically evaluating arguments which have been put forward in a dialogue. The basic idea is try to match the argument to one of the schemes in a large catalogue of schemes in order to, first, check that the scheme has been correctly applied and then, second, if one accepts the premises but is not yet persuaded that the conclusion is true, to use the critical questions associated with the scheme to try to defeat or at least weaken the argument.

Another use of schemes, which Doug has also investigated (Walton and Gordon 2012, 2017, 2018), is for constructing or, as Doug prefers to say, 'inventing' arguments to put forward in a dialogue. Here, a participant in the dialogue can refer to a catalogue of argumentation schemes to try to find some which may be applicable and useful for supporting or attacking some claim of the dialogue.

A third use of argumentation schemes is to allocate the burden of proof in dialogues. With regard to burden of proof, critical questions are of two kinds:

Assumptions Some critical questions, once they have been asked, create a burden of proof on the party who put forward the argument to provide an argument supporting the questioned premise. That is, the premise is assumed to be true unless it is questioned, after which it is no longer assumed but must be supported by further arguments and evidence. An example of this kind of critical question is the expertise question of the expert witness testimony scheme. The witness may be assumed to be an expert unless his expertise is questioned, at which point the party who made the argument must provide evidence of the expertise of the witness.

Exceptions The other kind of critical question expresses an exception. Here the burden of proof is placed on the respondent, the party challenging the argument by asking the critical question, to provide an argument proving the excep- 
tion holds, thereby undercutting the first argument. The trustworthiness critical question of the expert witness testimony scheme is of this kind. If the respondent questions the trustworthiness of the witness, he or she must provide an argument proving the witness is not trustworthy.

When used to regulate the burden of proof in dialogues, argumentation schemes become part of the protocol or procedural rules of the particular dialogue type or procedure. There are many types of dialogues and such protocols or procedural rules are norms for regulating and conducting dialogs of the given type, in order promote the values and goals of the dialogue type. Since argumentation schemes are context-dependent, particular schemes can be developed for specific, domain-dependent dialogue types. For example, in the law, specific legal norms can be interpreted as argumentation schemes for allocating the burden of proof in each legal domain, such as criminal or contract law.

As can be seen from the use of argumentation schemes to regulate the burden of proof in dialogues, argumentation schemes can serve a normative function. Schemes, however, can also be studied from an empirical perspective. One can identify and classify common patterns and forms of argumentation in different contexts, such as everyday conversation, academic discourses or in the law. This is something that Doug has done extensively and is one of his main contributions to the topic of argumentation schemes (Walton 1996; Walton et al. 2008). His latest compendium, from 2008, written with Chris Reed and Fabrizio Macagno (Walton et al. 2008) is a collection of 96 common argumentation schemes.

Let us end this brief overview of Doug's work on argumentation schemes with a discussion about some related work, to help to put his contribution into a broader context. Doug does not claim to have invented the idea of an argumentation scheme. Forms of argument have long been recognized and studied in philosophy, going back to at least Aristotle's study of the topics (Slomkowski 1997). In Walton (2005), p. 10, Doug cites (Hastings 1963; van Eemeren and Grootendorst 1992; Kienpointner 1992) as more immediate sources.

Toulmin's analysis of the form of argument (Toulmin 1958) is related but quite different from the argumentation schemes developed by Doug. Toulmin's analysis was at a different level of abstraction. Toulmin identified parts of an argument (e.g. datum, warrant, claim, and backing) and showed how such arguments are used in dialogues, but he did not study extensively more specific forms of argument, such as argument from expert witness testimony.

Prior to Doug's work on argumentation schemes, a much greater emphasis was placed in philosophy on studying fallacies (Hamblin 1970), that is, bad or misleading forms of argument. Argumentation schemes complement fallacies, by describing and analysing good forms of argument. To some extent argumentation schemes may be seen as challenging a basic premise of fallacies, if one takes the position that only arguments in which the conclusion is necessarily true are not fallacious. From the perspective of argumentation schemes, 'fallacious' arguments may be weak or defeasible arguments, but not necessarily improper or useless. Moreover, which forms of arguments to admit for use in a particular dialogue type is, from the perspective of argumentation schemes, a normative issue to be addressed when 
deciding which procedure and schemes are best suited for achieving the goals of the particular dialogue type.

Argumentation schemes also need to be contrasted with the inference rules of the axiomatization of some logic, such as modus ponens in an axiomatization of classical logic. Although they have syntactical similarities, they are quite different semantically and pragmatically. A collection of argumentation schemes can not, by itself, formalize or axiomatize a logic, because argumentation schemes are expressed informally, in natural language, and are not sufficiently abstract, as they contain domain-specific terms and predicates. Although it is possible to formalize argumentation schemes (Walton and Gordon 2015), it is then the schemes which are being formalized, rather than being used as tools to formalize a logic.

This is not the place to try to assess Doug's contributions to the study of argumentation schemes, to try to clarify exactly which parts of his work on argumentation schemes was original or can be attributed to prior work from other sources. Doug's work on argumentation schemes was important and influential not only because of its originality, but also because of his dedication and tireless efforts to explain, illustrate and apply the theory of argumentation schemes in various domains, through extensive interdisciplinary collaboration.

\section{Katie Atkinson: persuasive argument in practical reasoning}

Doug's influence on my own research career took effect right at the very start of my Ph.D. studies. I commenced my Ph.D. with a clear idea that I wanted to investigate argumentation and negotiation through formal dialogue models, but with little certainty as to the precise research question which I would address through these studies. I read Doug's book, The New Dialectic (Walton 1998b), early on in my first year of Ph.D. study and this provided me with a sharper focus for a particular subject of study. In that book, Doug sets out a precise characterisation of the different types of dialogue, which were identified in an earlier book [Commitment in Dialog (Walton and Krabbe 1995)] that he co-authored with Erik Krabbe. As described in the previous section, each of the dialogue types identified is given a characterisation in terms of the starting position, overall dialogue goal and individual participants' goals over what they wish to achieve through the dialogue. The persuasion dialogue type became the focus of my Ph.D. work since this encompasses the type of adversarial arguments I wished to study.

As well as studying the modelling of formal dialogues, which aligned with the interests and expertise of one of my Ph.D. supervisors, Peter McBurney, I was also studying the recent work of my other supervisor, Trevor Bench-Capon. Trevor had recently published his seminal paper on value-based argumentation (Bench-Capon 2003) and at that time we were discussing the application of valuebased reasoning in law. In doing so, we were considering reasoning problems that were focussed on justifying the outcome of actions in reasoning about legal cases, e.g. find for plaintiff, or find for defendant. We were considering these problems from the viewpoint of persuasive dialogue, but found that a nuance within the usual characterisation of persuasion was lacking: we needed our formal model of 
persuasion to distinguish between persuasion about what to believe and persuasion about what to do. Whilst persuasion over beliefs was undoubtedly an important topic to model, Dungian abstract argumentation frameworks (Dung 1995), provided sufficient tools for tackling this problem for our purposes. Conversely, reasoning about what to do, had not yet been articulated in a sufficiently expressive form to enable value-based reasoning to be captured to model the domain applications we were considering, mainly in law. This is where Doug's argumentation schemes came into play.

Reasoning about what to do-herein referred to as practical reasoning-can be regarded as a species of presumptive argument that gives a reason for performing an action. However, this presumption can be challenged and withdrawn. Subjecting an argument to appropriate challenges is how we hoped to identify and consider any alternatives that require contemplation, and ultimately determine the best choice for the individual(s) making the decision, in the particular context. To cite a simple example based on the practical syllogism (Kenny 1978):

I'm to be in London at 4.15.

If I catch the 2.30, I'll be in London at 4.15 .

So, I'll catch the 2.30 .

Challenging this argument:

- There may be alternative ways of achieving the goal.

- Performing an action typically excludes the performance of other actions, which might have other more desirable results.

- Performing an action make have further unconsidered, undesirable consequences, that may be sufficiently bad to lead us to abandon the goal.

These considerations are addressed within Doug's account of presumptive reasoning, as given in Walton (1996), which captures such reasoning in terms of argumentation schemes and critical questions. The idea is that an argumentation scheme gives a presumption in favour of its conclusion. Whether this presumption stands or falls depends on satisfactory answers being given to the critical questions associated with the scheme. In Walton (1996) Doug gave two schemes for practical reasoning:

1. The necessary condition scheme:

$\mathrm{G}$ is a goal for $a$

Doing A is necessary for $a$ to carry out $\mathrm{G}$

Therefore $a$ ought to do A.

2. The sufficient condition scheme:

$\mathrm{G}$ is a goal for $a$

Doing A is sufficient for $a$ to carry out $\mathrm{G}$

Therefore $a$ ought to do A.

Associated with these schemes are four critical questions: 
- $C Q 1$ Are there alternative ways of realising $\mathrm{G}$ ?

- $C Q 2$ Is it possible to do A?

- CQ3 Does $a$ have goals other than $\mathrm{G}$ which should be taken into account?

- CQ4 Are there other consequences of doing A which should be taken into account?

In Atkinson et al. (2006b) these schemes were taken as a starting point and expanded to cover a wider, more fine-grained range of relevant considerations covering consequences of actions, achievement of goals and promotion of social values by execution of actions. This expanded scheme for practical reasoning is as follows:

In the circumstances $\mathrm{R}$.

we should perform action A.

to achieve new circumstances $S$.

which will realise some goal G.

which will promote some value V.

The expanded argumentation scheme gives rise to an expanded set of critical questions as follows:

- $C Q 1$ Are the believed circumstances true?

- CQ2 Assuming the circumstances, does the action have the stated consequences?

- CQ3 Assuming the circumstances and that the action has the stated consequences, will the action bring about the desired goal?

- CQ4 Does the goal realise the value stated?

- CQ5 Are there alternative ways of realising the same consequences?

- CQ6 Are there alternative ways of realising the same goal?

- $C Q 7$ Are there alternative ways of promoting the same value?

- $C Q 8$ Does doing the action have a side effect which demotes the value?

- $C Q 9$ Does doing the action have a side effect which demotes some other value?

- $C Q 10$ Does doing the action promote some other value?

- CQ11 Does doing the action preclude some other action which would promote some other value?

- CQ12 Are the circumstances as described possible?

- $C Q 13$ Is the action possible?

- CQ14 Are the consequences as described possible?

- $C Q 15$ Can the desired goal be realised?

- $C Q 16$ Is the value indeed a legitimate value?

This natural language description of the scheme and critical questions provides a template for instantiation to enable proposals for what to do to be made and critiqued in a wide range of domains, including the legal domain where an early example in Greenwood et al. (2003) $)^{1}$ set out to apply this to case-based reasoning. The

\footnotetext{
${ }^{1}$ This paper is one of two I published in 2003 under my prior surname of Greenwood.
} 
next step undertaken was to automate this reasoning to turn it into an account that could be used by autonomous agents.

To give both the argumentation scheme and the critical questions precise interpretations, a semantic structure was used as the basis for their definition: this structure is an Action-based Alternating Transition System (van der Hoek et al. 2007). An AATS comprises states with actions labelling transitions between states, and these actions have pre-conditions that must be met to enable the action's execution. States comprise sets of propositions, so goal states can be identified by propositions that hold true in a given state. The original specification of an AATS did not account for the notion of values, so to allow for this and enable specification of the practical reasoning argumentation scheme, the definition of an AATS was extended to associate the promotion and demotion of values with state transitions. As well providing the required formalisation, the AATS enables consideration to be given of a society of agents and their differing choices such that the reasoning can capture decision making of an individual agent whilst also taking into account what other agents in the environment might choose to do. In an AATS this is captured through the notion of joint actions ${ }^{2}$.

In Atkinson and Bench-Capon (2007) it was shown how the practical reasoning argumentation and its critical questions could be given a precise, rigorous definition in terms of an AATS to enable this account of practical reasoning to be used in agent systems. That account shows, through a detailed worked example, how to instantiate the formal version of the scheme and critical questions to enable the generation of a set of arguments for and against a proposal for action. Once generated, these arguments then need to be evaluated to determine, from the competing set within the debate, which arguments are the winning ones and why. At our disposal for this task were value-based argumentation frameworks (VAFs), as had already been defined by Bench-Capon (2003).

The nodes in a VAF correspond to the arguments generated through instantiation of the practical reasoning argumentation scheme and instantiation of its associated critical questions. The attack relation is determined by instantiations of critical questions that subject the original proposal for action to scrutiny. Once the VAF representing the debate is determined, the VAF is evaluated to determine which of the competing proposals for action is the winning one. This is decided by applying the audience's preference ordering over values, since multiple instantiations of the practical reasoning argument scheme will yield different proposals for action, promoting different values. A full example showing how to generate and evaluate practical reasoning arguments using AATSs and VAFs is given in Bench-Capon et al. (2012).

The formalisation described above enables the informal version of the practical reasoning argumentation scheme to be turned into a computational account. A longer commentary on this exercise is provided by Trevor and myself in the paper that we contributed to Doug's Festschrift in 2010 (Bench-Capon and Atkinson 2010). However, the move from the informal to the formal account as described

\footnotetext{
${ }^{2}$ In an AATS joint actions are simply actions performed simultaneously by different agents: no idea of cooperation or coordination is intended.
} 
above overlooks the dialogical nature of argumentation schemes that has been a focus of Doug's work.

In my own work, I have together with other collaborators developed computational accounts of various types of dialogue from the Walton and Krabbe typology, including persuasion (Atkinson 2005), deliberation (Tolchinsky et al. 2012) and inquiry (Black and Atkinson 2009). Over a number of years I had discussions with colleagues in the computational argumentation community about the nuanced characterisation of persuasion over action and deliberation dialogues. In 2013 Doug, Trevor and I tackled this topic to provide an account that illuminated the distinctive features of persuasion and deliberation dialogues (Atkinson et al. 2013b). The motivation for the paper goes back to some of Doug's earlier insights regarding the importance of recognising the distinctions between dialogue types, since participants in both types of dialogues will have different aims, which in turn affects whether a successful outcome can be reached.

Persuasion over action and deliberation dialogues are typically conducted by exchanging arguments for and against particular options whereby the moves of the dialogue are designed to facilitate such exchanges. Our account showed how the pre- and post-conditions for the use of particular moves in the dialogues are very different depending upon whether they are used as part of a persuasion over action dialogue or a deliberation dialogue. We drew out the distinctions through an example (based on a dialogue about choosing a restaurant to eat at) presented as a logic program in order to give a clear characterisation of the two types of dialogues and enable them to be implemented within systems requiring automated communication. In 2019 this line of work was taken forward in a student project at the University of Liverpool, published in Kirchev et al. (2019), which presented an implemented tool that captures the distinctive features of each of the two dialogue types, to make plain their differences and to validate the speech acts for use in practical scenarios. The starting point for that paper can clearly be traced back to the dialogue typology presented in Walton and Krabbe (1995); the relevance of Doug's work for dialogue models for AI is still being shown 25 years after the typology was first published.

From a personal perspective, I have had the honour of discussing Doug's work and my own research with him at length on two particular occasions (in addition to the many enjoyable meetings we had at academic conferences). The first occasion was during my Ph.D. studies where I was invited to be the designated respondent for a talk that Doug was delivering at the Norms, Reasoning and Knowledge in Technology workshop, held in Boxmeer, The Netherlands in June 2005. The paper that Doug presented was titled Evaluating and Implementing Practical Reasoning and I was delighted to be the respondent for his talk to speak about implementation of systems based on informal logic models of practical reasoning, and in particular the development of such tools for e-democracy applications (Atkinson et al. 2006a) which were of interest to the legal field. Doug was very welcoming to junior researchers and generous with the time he gave listening to and talking through old and new ideas on argumentation. The second occasion I refer to was the viva voce examination for my Ph.D. degree in 2005 at which Doug served as the external examiner. I felt very lucky to have had the opportunity to discuss my research in depth with such an esteemed contributor to the field of argumentation theory who influenced my own 
work and whose legacy can be seen in a wide range of work on argumentation in AI and Law.

\section{Trevor Bench-Capon; driving dialogues with critical questions}

Before taking up computer science I studied philosophy and worked in a policy branch of the Civil Service. Thus I have always been attracted by argument (BenchCapon 2012a). Initially I used argument to explore notions of open texture (BenchCapon and Sergot 1988). The notion of argument there was simply the proof trace of a logic program. This is a rather impoverished form of argument, missing such important features as the use of enthymemes, the treatment of exceptions, and the reason why the conclusion follows from the premises. All of these features can be found in Toulmin's argument scheme (Toulmin 1958). Accordingly I, like several others (e.g. Lutomski 1989; Marshall 1989), adopted that scheme for the explanation of logic programs (Bench-Capon et al. 1991). Toulmin's scheme was well suited to presentation of arguments, but generation was done using the underlying logic program. I also used Toulmin's scheme to drive dialogues. The idea was that the various dialogue moves would navigate Toulmin's structure. This was used for explanation in Bench-Capon et al. (1993) and as the basis of a persuasion dialogue in Bench-Capon (1998a). In these dialogues, the computer would generate the argument as in Bench-Capon et al. (1991), and then reveal the scheme in response to questions from the user. By the late $90 \mathrm{~s}$, I felt that I had gone as far as I could with Toulmin's scheme, and began to take more interest in abstract argumentation (Dung 1995), especially as extended to support reasoning with social values (Bench-Capon 2003; Bench-Capon and Sartor 2003).

It was against this background that I encountered Doug Walton's seminal book on argumentation schemes (Walton 1996). From this I learnt three important lessons:

- there is not just one argument scheme: there are many;

- there is not a fixed set of argument schemes: one can develop one's own for particular purposes;

- and, most significant of the three, argument schemes are associated with characteristic critical questions which provide ways to attack arguments based on the schemes.

Also around this time I encountered a second of Doug's works, which developed the notion of dialogue types (Walton and Krabbe 1995). Together these two works reawakened my interest in dialogues and argumentation schemes, and have formed the basis of a great deal of my subsequent work.

In 2002 I had begun to supervise a Ph.D. student ${ }^{3}$, Katie Atkinson. Her thesis was to become What Should We Do? (Atkinson 2005). We explored the topic of practical reasoning through the use of a particular dialogue type taken from (Walton and

${ }^{3}$ Co-supervised with Peter McBurney. 
Krabbe 1995), persuasion dialogues, and by the development of a particular argument scheme for value based practical reasoning and its associated critical questions, inspired by two schemes from Walton (1996), together with Perelman's notion of an audience (Perelman and Olbrechts-Tyteca 1969) as expressed computationally in Bench-Capon (2003). The first appearance of our new scheme was in Atkinson et al. (2004). The key difference between the scheme inspired by Doug and my previous use of the Toulmin scheme was that Doug's schemes enabled the generation of competing arguments through the instantiation of the scheme and its critical questions. These arguments could then be organised into and evaluated using value based argumentation frameworks (Atkinson and Bench-Capon 2007). I will say no more about these aspects as they have already been discussed by Katie in the previous section.

I shall, however, discuss the influence of critical questions on dialogue design. Katie did implement a dialogue system (PARMA) in Atkinson (2005), but here I shall focus my work with another Ph.D. student ${ }^{4}$, Maya Wardeh, (Wardeh 2010), whose primary aim was to explore persuasion dialogues based on the discovery of association rules. For this purpose we first developed a dialogue protocol (PADUA). This protocol was entirely based on an argumentation scheme and its critical questions. These were first described in Wardeh et al. (2007). We called the scheme Argument from Proposed Rule with four premises:

1. Data premise There is a set of examples D pertaining to the domain.

2. Rule premise From $\mathrm{D}$ a Rule $\mathrm{R}$ can be mined with a level of confidence greater than some threshold T. R has antecedents A and a conclusion which includes membership of class $\mathrm{C}$.

3. Example premise Example E satisfies A.

4. Conclusion $\mathrm{E}$ is a $\mathrm{C}$ because $\mathrm{A}$.

This can be subject to a number of critical questions:

1. Can the case be distinguished from the proposed rule?

2. Does the rule have unwanted consequences?

3. Can the rule be strengthened by adding additional antecedents?

4. Can the rule be improved by excluding unwanted consequences?

5. Is there a stronger counter rule?

There were six legal dialogue moves based on instantiating the scheme and the critical questions. The inspiration of Doug's (Walton 1996) conception of argumentation schemes in is evident in this scheme and its critical questions. Maya's work gave a convincing demonstration of the utility of argumentation schemes and critical questions as the basis for dialogue design. The dialogues are a great improvement on the Toulmin based dialogues such as Bench-Capon (1998a), since they offer a genuinely

\footnotetext{
${ }^{4}$ Co-supervised with Frans Coenen.
} 
adversarial dialogue (the two players are mining different data sets), rather than the presentation of a computation which has been done prior to the dialogue. PADUA (and its development PISA which supported more than two players) was, by its ability to challenge the arguments, able to refine the rules to achieve a high level of accuracy [e.g. around $95 \%$ using a commonly used AI and Law dataset (Wardeh et al. 2009)].

This idea of using an argumentation scheme and critical questions to specify a dialogue was also used in the e-participation system PARMENIDES (Atkinson et al. 2006a), initially developed by Atkinson (2005), which was based on the practical reasoning argumentation scheme and a selection of its critical questions. After further refinement by Katie and her student (Cartwright and Atkinson 2009), this work was subsequently developed into the Structured Consultation Tool (SCT) of the IMPACT project ${ }^{5}$ The SCT enabled a member of the public to receive a detailed, tailored, justification of a policy proposal, or for the member of the public to present a proposal for critique (Wyner et al. 2012). The fullest account of the SCT is in Bench-Capon et al. (2015).

As well as driving dialogues, it is also possible to use argument schemes to capture reasoning methods (Prakken 2010). That is, a whole method for a particular kind of reasoning can be expressed as a cascade of argumentation schemes and their critical questions. My attempts to do this centred around the method for reasoning with precedent cases that is found in CATO (Aleven 1997), which has proved quite central to AI and Law accounts of case based reasoning (Bench-Capon 2017). The first attempt was made in Wyner and Bench-Capon (2007) in which the various argument moves of (Aleven 1997) such as citing, distinguishing and downplaying were expressed in a set of argument schemes. Thus use of argument schemes permitted a precise characterisation of the actions and a helpful visualisation of the reasoning. The schemes were applied to Popov versus Hayashi in Bench-Capon (2012b). These schemes were further refined in Wyner et al. (2011). Schemes to enable reasoning with values were given in Bench-Capon et al. (2013) and schemes using dimensions rather than simple factors were presented in Atkinson et al. (2013a). A consolidation of this line of work was made in Prakken et al. (2015). A similar approach to capture practical reasoning as a set of argumentation schemes was made in Atkinson and Bench-Capon (2014), and to reasoning about the actions of other agents in Atkinson and Bench-Capon (2018). In all these cases I found argumentation schemes a very fruitful way to think about these problems, and to express the reasoning involved.

The growing importance of argumentation in AI has been a story of this century. But whereas in general AI abstract argumentation has had the bigger impact, AI and Law has always seen the structure of arguments as of key importance. Doug's conception of argumentation schemes combines two important aspects of legal argument: the inherent defeasibility, and the adversarial nature of the process. In consequence, Doug's work has provided a lens through which to view legal reasoning,

\footnotetext{
5 Integrated Method for Policy making using Argument modelling and Computer assisted Text analysis. An FP7 project, Grant Agreement No. 247228.
} 


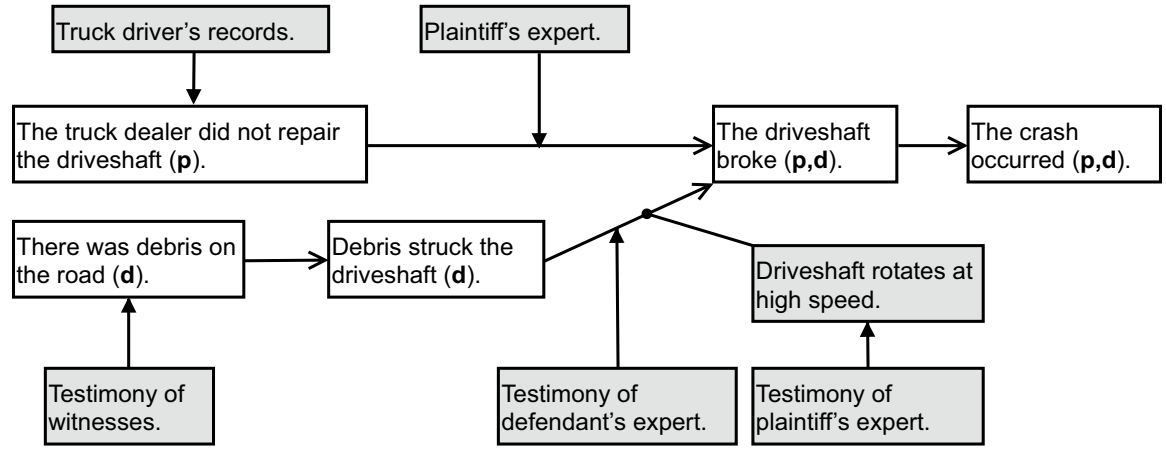

Fig. 1 Two stories with supporting and attacking evidential arguments, taken from Bex and Walton (2012). Arrows with an open arrowhead denote causal links (stories), arrows with a closed arrowhead denote evidential links (arguments) and an arrow with a rounded (dot) arrowhead denotes an attack of an argument on a story

and he has had a profound influence on the way the subject has developed over the last two decades.

\section{Floris Bex; from arguments to stories and explanations}

I first came into contact with Doug's work as an undergraduate in 2003. I was doing a research internship with Henry Prakken, comparing three formalisms for reasoning with evidence in the law: Pollock-style argumentation (Pollock 1987; Prakken and Sartor 1997), abductive model-based reasoning (Lucas 1997; Josephson and Josephson 1996) and Bayesian networks (Huygen 2002). The comparison was done by modelling a Wigmore chart (Wigmore 1937) of the well-known Sacco and Vanzetti case (Kadane and Schum 2011) in all the three formalisms. The argumentationbased modelling of the case was subsequently used in a paper (Bex et al. 2003 see Section 7.2) making Doug and me co-authors-though we wouldn't meet in person until $2007^{6}$. By that time I had already started my Ph.D., also with Henry Prakken, on formal models of stories and arguments in reasoning with evidence and facts in legal cases. During this Ph.D., I developed the so-called hybrid theory of stories and arguments (Bex 2011), a mixture of argument-based and story-based reasoning.

In argument-based reasoning, arguments are constructed by performing consecutive reasoning steps from evidence to conclusion. Each of these reasoning steps has an underlying evidential generalisation of the form "e is evidence for p". Reasoning with arguments is dialectical because not only arguments for a conclusion but also counterarguments are considered. Story-based reasoning involves constructing stories about what (might have) happened in a case to explain the evidence. Reasoning

\footnotetext{
${ }^{6}$ Either at that year's ICAIL conference in Stanford or the visualising evidence symposium organised by Peter Tillers in New York.
} 
with stories can be characterised as causal reasoning: the relations between the events in a story and between the story and the evidence can be expressed as causal generalisations "c is a cause for e". This approach is also dialectical: an explanation is defeasible, that is, it holds tentatively by placing a burden on an opponent to critically question it and to offer a possible alternative explanation.

In the hybrid approach, stories and arguments are combined for reasoning about the facts of a case. Stories can be used as hypothetical scenarios about "what happened" in the case, to explain the main observations. Arguments can then be used to argue about these stories. For example, arguments based on evidence can be used to support or attack stories (or each other). Figure 1 shows an example of two stories explaining a crash in the Anderson versus Griffin case (397 F.3d 515), taken from Bex and Walton (2012). Here, there are two stories about why the crash occurred. While both stories agree on the fact that the driveshaft broke, the plaintiff (p) argued that the truck dealer did not repair the driveshaft, whereas the defendant (d) argued there was debris on the road, which struck the driveshaft, causing it to break.

\subsection{Schemes and critical questions in the hybrid theory}

When reasoning with the evidence and facts in a case, we use a large amount of knowledge about the world we live in. This knowledge is not based on the specific evidence in the case, but rather it is the common sense knowledge we often take for granted, for example, 'experts normally speak the truth', or 'Murders often involve a weapon'. Such pieces of common sense knowledge, or generalisations, have varying degrees of reliability — some of it may be based on false beliefs or stereotypes, and for every generalisation there is a situation in which it does not hold ${ }^{7}$. It is therefore important that we critically analyse and question the common sense knowledge we use when reasoning with evidence. Here, the link with Doug's argumentation schemes and their critical questions becomes clear.

With respect to argumentation schemes, we can see that many argumentation schemes are evidential generalisations (Walton 2002, see also Section 7.2). Take, for example, the argumentation scheme for expert evidence (Sect. 2.2): the fact that 'expert $E$ asserts that proposition $A$ is true' is evidence for ' $A$ is true'. Critical questions point to possible counterarguments - a negative answer to the question 'Is $E$ an expert in the field that A is in?' can be seen as an exception to the generalisation that experts usually can be believed.

Stories are also based on general schemes or story schemes [also called scripts (Schank and Abelson 1977)], which represent general knowledge of stories, how certain situations normally develop. For example, the well-known 'restaurant-script' contains information about the standard sequence(s) of events that take place when somebody goes to dine in a restaurant. Story schemes mention not only a sequence of events, but also other information important in a story of that particular type. Take, for example, the story scheme for 'murder' (Bex 2011):

\footnotetext{
7 Since this generalisation is true, it is itself the situation in which it does not hold.
} 
1. Anomaly that the scheme explains person $y$ is dead.

2. Central action of the scheme person $x$ kills person $y$.

3. Other relevant information the motive $m$, the time of the killing $t$, the place of the killing $p$, the weapon $w$.

4. Pattern of actions person $x$ has a motive $m$ to kill person $y$-person $x$ kills person $y$ (at time $t$ ) (at place $p$ ) (with weapon $w$ ) - person $y$ is dead.

5. More specific kinds of murder assassination (e.g. liquidation), felony murder (e.g. robbery murder), killing of one's spouse.

In addition to a pattern of actions, this scheme also contains other information, such as what the central action is and which other, more specific schemes might be applicable. Other story schemes are more abstract: for example, (Pennington and Hastie 1993) mention an abstract episode scheme for intentional actions, a pattern of the form motive-goal-action-consequences.

Story schemes are important when reasoning about the evidence and facts in criminal cases: they are used to explain events, as they connect an event with an explanation that has been used to explain that sort of event before. When faced with some initial evidence, people draw on a range of standard scenarios (i.e. story schemes). For example, when a body is found in a house, the initial schemes police investigators use are 'murder', 'accident' and 'suicide'.

In addition to aiding explanatory inference, story schemes can also be used to critically analyse existing stories and, in particular, the coherence of stories. For example, if a story does not fit a particular scheme because some of the elements of the scheme are not in the story (for example, no mention is made of the motive in a murder story or the causal link between the murderous action and the victim's death is not made clear), the story's coherence diminishes. Like arguments, stories in evidential reasoning are dialectical, and critical questions associated with a story scheme can point to counterarguments. Note, for example, the similarity between the elements of Pennington and Hastie's intentional action scheme (motive, goal, action, consequences) and the argumentation scheme for practical reasoning (discussed in Sect. 3). This means that the critical questions of the scheme for practical reasoning can used to question and analyse motives and actions of characters in stories (Bex et al. 2014). For example, for a murder story we can ask the following questions.

1. Did person $x$ have the opportunity to kill person $y$ ?

2. Is motive $m$ a legitimate motive for killing?

3. Would $x$ have a reason not to kill $y$ ?

Critical questions can also be used to analyse more complex reasoning. In fact, Bart Verheij and I considered critical questions not just for individual argumentation or story schemes but also for the process of reasoning with stories and arguments as a whole (Bex and Verheij 2012). Thus, we proposed three types of critical questions that are useful when reasoning with evidence: (1) critical questions associated with the argumentation schemes, which can be used to analyse 
arguments based on evidence; (2) critical questions associated with the story schemes, with which the hypothetical stories about the facts may be analysed; and (3) critical questions for a hybrid argumentative-narrative case analysis, which may be used to analyse the case as-a-whole, that is, the combination of stories and arguments supporting or attacking these stories. Some examples of the latter as are follows.

1. Are the facts of the case made sufficiently explicit in a story? Is the story sufficiently coherent? Are there elements missing? Are there implausible elements in the story?

2. Is the story sufficiently supported by evidence? Is the support that the evidence gives to the story sufficiently relevant and strong?

\subsection{Burdens and standards of proof for the hybrid theory}

Even though we had been co-authors since 2003, it would not be until after my Ph.D. when we would first actively work together as co-authors (Bex and Walton 2010). In 2010 I visited Doug in Windsor, and I vividly remember the walks along the waterfront and our conversations. We talked about argumentation, explanation and the burden of proof, about which Doug had already published quite extensively, also with some of the other authors of this paper (Prakken et al. 2005; Gordon and Walton 2009b). We set to work looking if some of Doug's earlier ideas could be applied to the hybrid theory, which after a Jurix article (Bex and Walton 2010) would culminate in a paper in Law, Probability and Risk (Bex and Walton 2012).

In their argumentative account of burdens of proof, Prakken and Sartor (2009) define three kinds of burden of proof in terms of claims and the arguments for these claims. We applied their definitions to stories and arguments for and against these stories. Having the burden of persuasion for a story $S$ means that at the end of the trial $S$ should be accepted as the correct explanation of what happened in the casein a civil case such as Anderson versus Griffin (Fig. 1) the burden of persuasion lies with the plaintiff. The tactical burden shifts throughout the case, and depends on which story that meets the standard of proof is currently the best. In the Anderson versus Griffin case, after the plaintiff has made his initial case based on the records, the tactical burden shifts to the defendant to come up with an alternative explanation. The burden of production may be met by providing evidence that directly or indirectly supports the story on which the burden rests. In the Anderson versus Griffin case, after the defendant has produced his story about the debris, the burden of producing the evidence for his story lies with the defendant.

Note that the notion of a burden of proof presupposes certain standards of proof. Here, we followed Doug's earlier work with Gordon and Walton (2009b). A story $S$ meets the scintilla of evidence (SE) standard if there is at least one justified argument based on evidence supporting $S$. A story $S$ meets the preponderance of evidence (PE) standard if it meets the SE standard and it is better than each alternative story $S^{\prime}$ - that is, $S$ is either supported by more evidence or contradicted by less evidence than $S^{\prime}$. This is the standard for civil cases such as Anderson versus 
Griffin, and the plaintiff's story seems to meet it -it has two supporting arguments and while the defendant's story also has two supporting arguments, it also has an attacking argument. For clear and convincing evidence (CCE), a story $S$ should be good in itself as well as much better than each competing story $S^{\prime}$. In order to be good, $S$ should be supported by many arguments and contradicted by few arguments. In order to be much better than any alternative $S^{\prime}, S$ should have either significantly more arguments supporting it, or significantly fewer arguments contradicting it. Finally, a story meets the beyond a reasonable doubt (BRD) standard if it meets the CCE standard and each competing story is very weak, so weak as to be highly implausible.

\subsection{Argumentation and explanation in dialogue}

During my visit to Windsor, Doug and I also started talking about the differences, similarities and interplay between argumentation and explanation ${ }^{8}$. The point is that, in a dialogue, argumentation and explanation are not always easily distinguishable. Logic textbooks (e.g. Hurley 2003) offer a pragmatic test to determine whether a passage expresses an argument or an explanation, where the focus is on the proposition or event that is to be explained or proved. If this proposition is not subject to doubt (e.g. it is generally accepted as true), the passage should be taken as an explanation. If it is subject to doubt, that is, if it is unsettled whether it is true or not, then the passage should be taken as an argument. The difficulty with this is that it is often hard to determine whether a proposition is "generally accepted as true", and that argument and explanation can only be properly distinguished by looking at the dialogical context of reasoning, that is, the original intention of the speaker (to argue or explain) but also at the utterance that was replied to and the beliefs and intentions of the audience.

If it is so difficult to distinguish argument and explanation, one could ask 'why bother?'. In our paper (Bex and Walton 2016), Doug provided a compelling reason. Circular arguments, where the conclusion of one argument is the premise of another argument and vice versa (i.e. $p$ therefore $q$; $q$ therefore $p$ ), can be viewed as an instance of the fallacy of 'begging the question'. However, in the case of explanation, circularity need not be a problem-in fact, there are many vicious (causal) circles that clearly explain why events happened as they did. For example, in the Anderson versus Griffin case (Fig. 1), it is conceivable that the debris striking the underside of the car caused new debris to fall on the road, which would then again strike the car.

As Doug and I argued, in a dialogue we should be clear if we are offering or asking for an explanation or an argument, as they are evaluated differently. Hence, in any formal dialogue game we need to have different speech acts for asking for and offering arguments and explanations.

${ }^{8}$ This subject has now again become a hot topic in the context of explainable AI, see e.g. Miller (2019). 


\subsection{Concluding: the dialectical stance}

Doug's ideas on argumentation schemes as representing general knowledge about dialectical reasoning had a profound impact on the hybrid theory. Particularly the idea of critical questions, which can and should be asked when reasoning with evidence in different ways, has influenced the hybrid theory, lifting it (particularly more informal versions of it) from a 'mere' knowledge representation theory to a more normative, dialectical theory that can be used to critically analyse one's reasoning. In this sense, Doug's work has taught me the true meaning of what, in what proved to be out last collaboration (Bex and Walton 2019), we called the dialectical stance ${ }^{9}$.

\section{Thomas Gordon: supporting argumentation with the Carneades system}

When I entered the field of AI and Law in 1982, shortly after finishing law school, I worked on the topic of legal expert systems in the legal informatics group headed by Herbert Fiedler at the German Society for Mathematics and Computer Science (GMD) in Sankt Augustin. As a law student at UC Davis, in California, I had constructed a small expert system for an area of US securities law in an independent study project, using the E-MYCIN rule-based system ${ }^{10}$ in collaboration with Stanford University. In my efforts to model legal norms using rule-based systems and the Prolog logic programming language, I began to appreciate that norms are typically defeasible, subject to exceptions, and became interested in nonmonotonic logics as a way to model such defeasible norms. However, as a result of also taking a deeper interest in work in legal philosophy on legal reasoning and argumentation, I soon came to view nonmonotonic logics, or indeed any kind of logic, as being too limited to fully capture legal reasoning and argumentation. The process not only applies rules deductively to facts to draw (defeasible) inferences, but also involves constructing these rules and facts by interpreting legal source texts and evidence, in a goal-directed way during legal procedures, which are multi-party argumentative dialogues. The parties in these dialogues take turns making speech acts, for example by raising issues, making claims, and constructing and putting forward arguments to support these claims. From a higher-level perspective, the goal of each party is to construct a theory of the law and the facts of the case which is more coherent and persuasive than the theory put forward by the opposing party, because of the reasons put forward in the arguments supporting and attacking the competing theories.

\footnotetext{
9 A stance is the level of abstraction on which decisions or behaviour are judged. Cf. Dennett's intentional stance (Dennett 1989), which views the behaviour of an entity in terms of the mental properties (intentions) of the entity. The dialectical stance views our reasoning behaviour in terms of arguments and counterarguments.

10 E-MYCIN, or essential MYCIN, was a version of the pioneering expert system MYCIN (Shortliffe and Buchanan 1985) with the domain knowledge removed to be replaced by the user's own knowledge base.
} 
As a result of these insights, I began to view this procedural, dialogical approach to modeling legal reasoning and argumentation as an application of what I called "computational dialectics". Together with Ron Loui, I organized a workshop on computational dialectics as part of the AAAI conference in Seattle in 1994. Gerhard Brewka and I organized a second workshop on computational dialectics as part of the Formal and Applied Practical Reasoning (FAPR) conference, which took place in Bonn, Germany, in 1996.

It was at the FAPR conference that I first encountered Doug Walton. Doug gave one of the invited talks at the conference. And he took part in our workshop on computational dialectics. I remember him sitting quietly in the back of the room, listening attentively. I remember feeling honored that he would take an interest in our workshop. I am not longer sure, but I do not recall that we actually talked to each other on this occasion. So it may be that we did not really get to know each other more personally until a couple of years later.

In 1998 or 1999, about 2 years after the FAPR conference, Doug sent me a copy of his latest book, The New Dialectic. I was extremely surprised and honored that he closed the book with some very kind comments about my Ph.D. thesis, The Pleadings Game, which takes the dialectical perspective on legal reasoning and argumentation outlined above. I must have contacted him to thank him, and this was when we became better acquainted with each other.

However it would be a few years before, in 2005, we began our collaboration in earnest and wrote a paper together (Walton and Gordon 2005b). From that point on we published at least one paper together almost every year, except 2008 and 2013, up to and including 2018, about the time I retired. Altogether we published 19 papers together, over a period of 13 years. A selection of these papers is summarized below.

Our first joint paper was Critical Questions in Computational Models of Legal Argument (Walton and Gordon 2005b) in 2005. It compared my first attempt to model the critical questions of Doug's theory of argumentation schemes (Gordon 2005) with the approach proposed by Verheij (2003c). Both of us modelled critical questions as additional premises of arguments, which could then be used to attack the argument. The unique feature of my approach was that it included a computational model of various proof standards, similar to my prior work on Zeno (Gordon and Karacapilidis 1997), and allowed a different standard to be assigned each issue, that is to each contested premise, independently. Another advantage of my approach was that it distinguished different types of critical questions (called exceptions and presumptions) and assigned the burden of proof to the parties depending on the type. This allowed one to choose between the "shifting burden" and the "backing evidence" theories of critical questions (Walton and Godden 2005a), for each critical question.

The following year, in 2006, we published our first paper on the Carneades Argumentation Framework (Gordon and Walton 2006b) along with a paper showing how to use Carneades to model the arguments in the Pierson versus Post legal case (Gordon and Walton 2006a). Carneades grew out of the work discussed above (Walton and Gordon 2005b). In the early version of Gordon and Walton (2006b) it provided a formal model of the structure of a set of interconnected arguments, called 
"argument graphs" and of argument evaluation, using models of proof standards and burden of proof to determine which statements (propositions) are acceptable. This formal model was implemented in a software system, also called Carneades, for helping users to construct, evaluate and visualize argument graphs. The visualization method was similar to the one used in Araucaria (Reed and Rowe 2004), but with extensions for distinguishing different kinds of premises (ordinary, presumptions, exceptions). Soon thereafter Doug began using and promoting this and later versions of the Carneades argument diagramming method in his books and other publications. In 2007 a journal version of this work was published in Artificial Intelligence journal (Gordon et al. 2007). Henry Prakken joined us as a co-author and helped us in particular with proving some properties of the formal model.

In 2009, Doug and I contributed a chapter on formal models of proof burdens and standards to the book Argumentation in Artificial Intelligence edited by Rahwan and Simari (Gordon and Walton 2009b). While the chapter was mainly a survey and analysis of prior work, it also included an updated version of the Carneades formal model of structured argument and evaluation in Gordon et al. (2007), extended with formal models of dialogues, audiences, and the different types of burdens identified by Prakken and Sartor (2009): the burdens of claiming, questioning, argument production, persuasion, and the tactical burden of proof.

Also in 2009, Doug and I published our first paper together on how to integrate heterogeneous computational models of various argumentation schemes into a hybrid system for constructing and evaluating (legal) arguments (Gordon and Walton 2009a). The basic idea was to view argumentation schemes as abstract data types with methods for constructing arguments, where all such data types satisfy a common protocol, so that they can be used together to construct arguments graphs consisting of many arguments fitting different argumentation schemes. The argument graphs were then evaluated using the methods developed previously for Carneades, discussed above. We illustrated our approach with computational models of legal argumentation schemes for arguments from ontologies, rules, cases and evidence. This work was intended to realize the claim I made in my 2007 ICAIL keynote address, that the diverse forms of argument identified and modelled in the field of AI and Law could be subsumed under the concept of argumentation schemes and integrated into a common framework for legal reasoning based on argumentation (Gordon 2007). The computational models were implemented in the version of Carneades developed in the European ESTRELLA project (IST-4-027655).

In 2012, Doug and I contributed an article to a special issue of this journal, $A I$ and Law, about different approaches to modelling the arguments in the Popov versus Hayashi case, edited by Atkinson (2012), in which we modelled the arguments of the case using Carneades (Gordon and Walton 2012), using the same approach as we had used in our reconstruction of the arguments in Pierson versus Post in Gordon and Walton (2006a). The argument diagrams in the article were generated with a new, interactive argument diagramming application for Carneades developed by Matthias Grabmair in a Google Summer of Code project.

Also in 2012 Doug and I published an article in a philosophy journal about how a software tool such as Carneades can be used to help people to apply argumentation schemes to construct new arguments or, as Doug liked to say, to "invent" arguments 
(Walton and Gordon 2012). This is a good example of several articles that Doug published in philosophy conferences and journals, sometimes with me as co-author, about how artificial intelligence methods and tools in general, and Carneades in particular, can be useful for assisting people to apply theories of argumentation from philosophy to argue better in practice. Doug served as an influential ambassador between the philosophy and artificial intelligence communities. Another example is Walton et al. (2014), with Chris Tindale, where we used Carneades to reconstruct several arguments from ancient Greece philosophers, in particular the famous argument about whether an object was a rope or snake from Carneades, the philosopher, which had motivated us to name our system Carneades after him.

But perhaps the most significant example was published in 2015 in Informal Logic, entitled paradoxically and hopefully provocatively Formalizing Informal Logic (Walton and Gordon 2015). The field of informal logic was founded in the 1950s at a time when formal logic was synonymous with first-order predicate logic. Our aim was to show that newer formal models of reasoning and argumentation from the field of artificial intelligence, such as Carneades, can overcome the reservations philosophers in the 50s had about the limitations of formal methods for modeling real-life argumentation, and using these models as a foundation for practically useful software tools. We did this by showing how Carneades can successfully handle the ten basic characteristics, or requirements, of informal logic in the relevant philosophy literature.

During the period from 2016 to 2018 Doug and I published a series of papers on the latest and presumably final version of Carneades. The first, Formalizing Balancing Arguments, was presented at the Computational Models of Argument (COMMA 2016) conference (Gordon and Walton 2016). The paper presented a major improvement to the Carneades formal model of structured argument which allowed, for the first time, arguments to be weakened or, somewhat counterintuitively perhaps, strengthened, if a premise fails, rather that defeating the argument entirely. This enabled argument accrual to be handled, meeting all the requirements for accrual identified by Prakken (2005b) but in a computationally tractable way, without causing an exponential blowup in the number of arguments. It also fixed a limitation of the original version of the formal model of Carneades, by removing the restriction to acyclic argument graphs. This new version handles cycles using fixed-point semantics in a way similar to and inspired by Dung Abstract Argumentation Frameworks (Dung 1995), but in a direct way, without mapping structured arguments to abstract arguments, unlike ASPIC+ (Prakken 2010). The formal model was fully implemented in Version 4 of the Carneades argumentation system, for grounded semantics. The main theorem of our COMMA paper, about the monotonicity of the characteristic function, was left as a conjecture. The proof was provided later in Gordon (2018). However, unfortunately, Henry Prakken discovered a minor error in the proof via a counterexample (Prakken 2019), due to the definition of proof standards being unnecessarily broad and abstract. The error can be easily fixed by restricting the definition of proof standards to ones which are are commonly used in practice, such as the small number of legal proof standards provided by the implementation of the Carneades system. However this admittedly remains to be formally proven, and it is hoped that some ambitious doctoral student will take on this task some day. 
My final paper with Doug was published in Argument and Computation in 2018, along with my colleague at Fraunhofer, Horst Friederich (Gordon et al. 2017). In this paper we presented a programming language for argumentation schemes, based on Constraint Handling Rules (Frühwirth 2009), and validated the language by showing how twenty of Doug's most important argumentation schemes (as selected by Doug) can be represented in the language and used to automatically generate or 'invent' arguments from a set of assumptions. (Moreover, in the meantime, Başak Kurtuldu has used the language to represent many other of Doug's argumentation schemes, as part of her Ph.D. thesis, summarized in Kurtuldu (2019).) The generated arguments are represented using the latest version of the Carneades model of structured argument, and can then be evaluated by this model, for example with its support for cumulative arguments. Recall that in our previous work on representing argumentation schemes (Gordon and Walton 2009a), discussed above, we provided only a framework for integrating heterogeneous implementations of specific schemes. This work goes beyond this prior work by providing a very expressive, rule-based language for representing and implementing a wide range of argumentation schemes in a high-level, declarative fashion. Others have used various rulebased languages to represent some argumentation schemes, such as Verheij with DefLog (Verheij 2003c), but none of these languages were expressive enough to handle many of Doug's argumentation schemes, including his leading examples of argumentation schemes, such as the scheme for arguments from witness testimony, due to their lack of sufficient support for variables ranging over propositions.

Perhaps this was a fitting last paper for us to write together. With it, Doug and I achieved the goal of formalizing all of the main features of his theory of the structure of argument, argument evaluation in dialogs, and of argumentation schemes, with support for representing a broad range of schemes in a high-level language, including two kinds of critical questions, automatically generating arguments from these schemes, and evaluating the arguments with support for distributing the burden of proof, multiple proof standards, cumulative arguments, argument accrual, cyclic argument graphs, and generating visualizations of argument graphs in argument diagrams of the kind common in philosophy. ${ }^{11}$ Perhaps I should qualify this claim by saying that we achieved this goal to our mutual satisfaction. I have no doubt that others will find ways to take this work forward and to improve upon it in many ways. And perhaps some of our colleagues have already done so.

Let me close this section by reflecting a bit on why Doug and I enjoyed collaborating so extensively for such a long period of time. It was very easy for us to work together. Aside from Doug being so likeable, modest, curious and open to new ideas, I think it helped that we each had our own field of expertise. In our relationship, Doug was the philosopher and the expert on argumentation, while I was the computer scientist, software engineer and the one more experienced with the technical details of artificial intelligence. I viewed myself as the software engineer trying to build models and systems which meet the requirements identified by Doug in his theory of argumentation. I

\footnotetext{
11 The source code of all versions of the Carneades software is available on Github at https://github.com/ carneades.
} 
was always convinced that Doug's approach to argumentation, with his theory of argumentation schemes and dialog types, was very useful for the kinds of application scenarios that interested me in the legal domain, which require quite a number of different kinds of schemes to be applied together dialogically in legal procedures. I focused my energies on trying to make Doug's theory computational.

If I have one regret, it is that we did not find time to work more together on the topic of formally modelling legal dialogs, which had been the focus of my Ph.D. thesis (Gordon 1995). We had this topic on our joint research agenda, but sadly life is short.

\section{Henry Prakken: argumentation schemes and burdens of proof}

My interest in argumentation mainly stems from my interest in AI and Law. Since lawyers argue all the time, any study of how legal reasoning and decision making can be modelled or supported by AI tools will sooner or later have to deal with argumentation. Originally I saw the formal and computational modelling of legal argument as applying nonmonotonic logic. When I entered academia as a Ph.D. student in 1988, nonmonotonic logic was a trendy topic in AI, just 8 years after the famous special issue of Artificial Intelligence Journal on the topic (Bobrow 1980), and its relevance for legal reasoning seemed obvious. Although I was fascinated by the fashionable nonmonotonic logics of those days, like default logic and circumscription, I felt that something was missing for legal applications. It was especially the work in AI and Law on legal argument by Gardner (1987) and Rissland and Ashley (1987) that made me aware that the notion of an argument should be central. Other early sources of inspiration were general AI work by Poole (1985) and Loui (1987) [I was not yet aware then of the seminal work of Pollock (1987)]. I designed my first argument-based nonmonotonic logic in 1990, published as Prakken (1991) (although in that paper I did not use the term 'argument' but 'proof set'). Also in my work with Giovanni Sartor between 1995 and 1997 I mainly thought of formal argumentation systems as a kind of nonmonotonic logic, this time based on Dung's now famous abstract account of argumentation that he had just introduced in Dung (1995), and assuming that arguments are created by chaining domain-specific rules (legal, commonsense or otherwise) into inference trees. It was not until 2000, when I was a participant at the Bonskeid Symposium on Argument and Computation in the Scottish mountains, that I became familiar with Doug Walton's work. At this Symposium, organised by Tim Norman and Chris Reed, researchers from various formal and informal fields met in an informal setting. Doug was among the other participants. Various interdisciplinary collaborations resulted from this event, partly reported in Reed and Norman (2003).

\subsection{Walton's influence on my work: general remarks}

Doug Walton's work influenced me in two ways. First, I began to see the potential of an argumentation-scheme approach to the problem of finding the rules with which arguments are constructed [another source of inspiration here was John Pollock's account of the role of defeasible reasons in cognition (Pollock 1987, 1995)]. Second, 
I became interested in dialogue models of argumentation (although here I was more directly inspired by AI and Law work on modelling legal procedure). Below I discuss both topics in separate subsections. But before that I should mention that I deviated from Doug's views on these topics in one important respect. Doug did not see these topics as separate. He regarded argumentation schemes as essentially dialogical devices, determining dialectical obligations and burdens of proof [see e.g. the introduction of Walton (1996)]. Using this account, a procedure for evaluating arguments constructed with argumentation schemes should take the form of a set of dialogue rules. I instead argued in my paper for the 2010 Festschrift for Doug (Prakken 2010) that argumentation schemes are essentially logical constructs, so that a procedure for evaluating arguments primarily takes the form of a logic. (In Sect. 9 Bart Verheij mentions that he followed a similar approach with his DefLog system.) More specifically, I argued that most (though not all) argumentation schemes discussed by Doug can be seen as defeasible inference rules and that their critical questions can be seen as pointers to counterarguments, so that the logic governing the use of argumentation schemes should be a logic for defeasible argumentation. The dialogical role of argumentation schemes can then be modelled by embedding such a logic in a system for dialogue, so that in the end argument evaluation with argumentation schemes is a combination of logical and dialogical aspects. More specifically (see also Prakken 2005a), the dialogue protocol determines the relevant arguments, counterarguments and defeat relations at each stage of the dialogue. At each such stage the argumentation logic then determines the logical justification status of these arguments, after which the burden of proof shifts to the losing side to make herself win at a new dialogue stage, and so on. Thus the justification status of an argument depends on both logic and dialogue.

\subsection{Argumentation schemes}

Since I did not see how the simple rule-based approach of Prakken and Sartor (1996, 1997) could account for argumentation schemes, I looked for a different formal approach. Since I saw a parallel between the notion of an argumentation scheme and Pollock's notion of a defeasible reason, I initially adopted a simplified version of his formalism from Pollock (1994, 1995), noting that many of Doug's critical questions to argumentation schemes could be modelled as pointers to rebutting or undercutting defeaters. See e.g. Bex et al. (2003) and Prakken (2005b). The first two of these papers actually contain the claim that Pollock's work on defeasible reasons is an example of Doug's argumentation-scheme approach. I don't think that Doug (a co-author of these papers) agreed with this, but he generously allowed me to include this claim ${ }^{12}$. In Bex et al. (2003) we then semiformally sketched Pollock's

\footnotetext{
12 As an anecdote, on several occasions I tried to convince Doug that his notion of argumentation scheme was similar to Pollock's notion of a defeasible reason. Doug was never convinced. I later realised that this was since he saw argumentation schemes not as inference rules but as dialogical devices. In fact, Doug once told me that he and his wife had visited Pollock in Arizona. When I asked him whether they had talked about the relation between argumentation schemes and defeasible reasons, Doug answered that not a single word had been exchanged about this.
} 
way of defining arguments and his two kinds of attack, and then also semi-formally remarked that this account could be embedded in Dung's abstract approach. We then continued to propose a list of argumentation schemes for evidential reasoning, some coming from Pollock's work on defeasible reasons (perception, memory, the statistical syllogism, induction, temporal persistence) and some coming from Doug's work on argumentation schemes (general knowledge, expert testimony, witness testimony).

Later I changed from a Pollock-style formalism to the ASPIC ${ }^{+}$framework (Prakken 2010; Modgil and Prakken 2014, 2018), which originated from the EU-funded ASPIC project, ${ }^{13}$ running from 2004 to $2007 .{ }^{14}$ One aim in the ASPIC project was to consolidate the then state-of-the art in formal argumentation logics. To this end, we combined Vreeswijk's $(1993,1997)$ very elegant definition of an argument with Pollock's distinction between rebutting and undercutting attack (and we added premise attack or 'undermining attack'). ${ }^{15}$ We then incorporated the notion of a preference relation on the set of arguments to determine which attacks succeed as defeats, resulting in a set of arguments and a defeat relation. This allowed us to use Dung's semantics for abstract argumentation frameworks to evaluate the arguments.

Several publications since 2010 show how reasoning with argumentation schemes can be modelled in the ASPIC ${ }^{+}$framework, by regarding the schemes as defeasible inference rules and the critical questions as pointers to (rebutting, undercutting or undermining) attacks. For instance, in Modgil and Prakken (2014) Sanjay Modgil and I showed how a combination of Pollock's defeasible reasons for perception and Doug's scheme from the position to know can be formalised in ASPIC ${ }^{+}$. In Prakken et al. (2015) I, with Adam Wyner, Trevor Bench-Capon and Katie Atkinson, modelled schemes for case-based legal reasoning in ASPIC ${ }^{+}$. Moreover, in BenchCapon et al. (2011) Trevor, Wietske Visser and I used variants of Doug's argumentation schemes from good and bad consequences to formalise two-phase democratic deliberation, and in Prakken (2015) I used similar schemes in formalising debates about law-making proposals as practical reasoning. Based on this work I still believe that the view of argumentation schemes as primarily logical devices is a fruitful one. However, Doug was certainly right that there is a dialogical side to the evaluation of arguments. To this I now turn.

\footnotetext{
13 The ASPIC project was funded under FP6-IST, Grant agreement ID: 002307. Details can be found at https://cordis.europa.eu/project/id/002307 (last accessed May 2020).

14 I also briefly collaborated with Walton and Tom Gordon on the Carneades framework (Gordon et al. 2007), which essentially was Tom's brainchild influenced by Doug's philosophy, as described in Sect. 6. My contributions to Carneades were modest: I mainly helped with some technical issues. Tom very generously rewarded me with co-authorship.

15 As a historical aside, it was not us from Utrecht (Martin Caminada, Gerard Vreeswijk and myself) but the people from IRIT in Toulouse (Leila Amgoud, Claudette Cayrol and Marie-Christine LagasquieSchiex) who initially proposed to use Vreeswijk's definition of an argument and to combine it with Pollock's distinction between rebutting and undercutting attacks.
} 


\subsection{Dialogue systems}

The influence of Doug's ideas on my work on argumentation dialogues was initially more indirect, coming through AI and Law work on modelling legal procedure with dialogue games for argumentation (Gordon 1994; Hage et al. 1993; Lodder and Herczog 1995). This work was in turn inspired by a body of work in argumentation theory on so-called 'formal dialectics' [a term coined by Hamblin (1970)], to which Doug had made important contributions (e.g. Woods and Walton 1978; Walton and Krabbe 1995). A more direct influence came through my collaboration with Doug in Prakken et al. (2004, 2005). In those days Doug thought a lot about the problem whether asking a critical question always shifts the burden of proof in persuasion dialogues. He realised that sometimes just asking a critical question of an argumentation scheme is not enough to make the argument 'default' but something more is needed. Once argumentation schemes are seen as defeasible inference rules and their use is embedded in dialogue systems as sketched above, a natural solution to Doug's problem becomes available. When critical questions point at rebutting or undercutting counterarguments, then simply asking them is not enough to shift the dialogical burden of proof to the other side, since the idea of defeasible reasoning is that the absence of such counterarguments is presumed. So to shift the burden of proof, a counterargument must be provided. For instance, when an argument from expert opinion is offered, it is not enough to ask whether the person who is claimed to be an expert is biased, since in the absence of evidence to the contrary, experts are presumed to be not biased. Instead, when a critical question asks whether a premise of an argument instantiating a scheme is true, then the premise must be further supported, so simply asking whether it is true shifts the burden of proof. For example, that someone who is claimed to be an expert on a given issue really is an expert cannot simply be presumed but must be argued for when challenged. In my papers with Doug and Chris Reed on dialogue we modelled this approach by, at each stage of a dialogue, excluding the arguments with challenged premises from the set of arguments to which the argumentation logic is applied at that stage [an idea originally from Prakken (2005a)].

There is a technical subtlety here. In some (uses of) argumentation logics the absence of an exception is made explicit as a special type of premise [for instance, the 'assumptions' of assumption-based argumentation (Toni 2014), which can also be included in ASPIC + (Prakken 2010)]. In that case there are no undercutting counterarguments and whether a critical question about a premise shifts the burden of proof depends on whether the premise is an assumption or not. Only if it is not, does asking whether it is true shift the burden of proof. Despite this technical difference between various (uses of) argumentation logics, the general story is the same: logically speaking some things can be presumed in the absence of evidence to the contrary, while other things cannot; only in the latter case does asking whether the thing is true shift the burden of proof. See also the distinction between assumptions and exceptions made above in Sect. 2.1.

One point made in Prakken et al. $(2004,2005)$ is that whether something can be presumed or not is often a domain-specific issue, which can itself become the subject of debate. One example is legal procedure, where the distribution of the burden 
of proof over the parties can become the subject of debate. Accordingly, Doug, Chris and I proposed a dialogue system in which a challenge of a premises $\varphi$ of an argument can be answered with "you have the burden of proving $\neg \varphi$ because ...". Such a move makes the dialogue shift to an embedded burden-of-proof dialogue, the outcome of which determines whether the challenge of $\varphi$ has any dialogical effect. These ideas were formalised within my general approach to formalising persuasion dialogues proposed in Prakken (2005a).

After our two joint publications, Doug, Chris and I did not further pursue this line of research together, but our papers had a big influence on a series of papers I subsequently wrote with Giovanni Sartor on formal models of presumptions and burdens of proof in legal procedure, culminating in Prakken and Sartor (2009). One idea that Giovanni and I further developed was the distinction between the global and local burdens of proof, which was one of Doug's contributions to the two papers I wrote with him and Chris Reed. The global burden of proof remains fixed during a persuasion dialogue and rests on the proponent of the initial claim. By contrast the local burden of proof can shift during a dispute. As we wrote in Prakken et al. (2005):

Moves in which a proposition is asserted (either as a claim or as a premise of an argument) usually carry a burden with them to defend the assertion or else retract it when challenged. However, in exceptional cases the burden shifts to the other party to provide evidence that the proposition does not hold.

This agrees with the above-sketched way of embedding reasoning with defeasible argumentation schemes in dialogue protocols. In fact, in Prakken et al. (2004, 2005) we assumed that arguments as put forward in a dialogue are constructed with argumentation schemes seen as defeasible inference rules. Giovanni and I found that Doug's distinction between global and local burden of proof is related to a distinction in common law between the burden of persuasion on the one hand, and the burden of production and the tactical burden of proof on the other. We also further developed the idea proposed in Prakken et al. $(2004,2005)$ to model dialogues about the burden of proof, especially in Prakken and Sartor (2007).

To be honest, Giovanni and I found that Doug's ideas on burdens of proof were not the final answer; especially in legal contexts the notion of burden of proof is quite tricky; in Prakken and Sartor (2009) we distinguished no fewer than seven distinct types of proof burdens. But Doug's ideas definitely put us in the right direction.

\section{Giovanni Sartor: argumentation in legal interpretation}

I came to know Doug about two decades ago, at one of the many ICAIL conferences at which both of us participated. I remember that I enjoyed speaking with him, I liked his curiosity, and his availability both to provide his insights and to listen to less experienced researchers, coming from different domains

At that time, I had already been working, in particular with Henry Prakken, on developing formal models of legal reasoning based on logic programming, nonmonotonic logic and Dung-style argumentation. I felt committed to the project of developing formal models of legal knowledge and reasoning. I thought that such 
models, to be built by applying and extending ideas from logic and AI, would contribute not only to useful computer applications, but also to progress in legal thinking and legal practice. I was aware that research on argumentation and rhetorics-in particular some leading contributions, such as of Perelman and Olbrechts-Tyteca (1969), Toulmin (1958), and Viehweg (1993) — could provide many useful insights for the development of formal models of legal reasoning. However, in legal studies, in particular in the continental tradition, the appeal to the "informal", "rhetorical" or "topical" tradition was often presented in a polemic opposition to any application of formal, or even scientific, methods in the legal domain. It seemed that a legal theorist would have to choose on which side to stand, and given my interests and propensities, I was committed to the "formal" side, which implied being to some extent sceptical toward "informal logic." The encounter with Doug changed my perspective: he was a leading scholar in informal logic, but was interested in finding formal and even computable models that could capture, even though partially, the patterns of reasoning that he was detecting and investigating. Since his work on dialogue types with Walton and Krabbe (1995) he had engaged in this interdisciplinary research, meant to merge argumentation research and formal models. Moreover, he was interested in bringing this approach into the AI and Law domain, as shown by the contributions he was developing with some of my colleagues working in this domain.

I was very happy to be able to invite him for some months at the European University Institute. We had a well-attended course on argumentation in law, and we succeeded in doing some work together, which led to the following research projects.

\subsection{The rationale for argument schemes}

A first project concerned the justification of argument schemes. Doug's work had elicited a number of diverse argumentation schemes, well beyond the classical distinction of deduction, induction, abduction and analogy. He had also shown that reasoning patterns that were usually considered to be fallacies-arguments from authority, from precedent, from ignorance, from correlation to causality, etc.- - as they fail to meet the requirements of logical deduction, were accepted in a number of contexts and domains. However, such patterns could lead to mistaken conclusions, even when deployed in suitable contexts, due to their defeasible nature. This raised the issues of what would justify the fallible use of a defeasible reasoning pattern, in what contexts. A second issue was to explain why certain patterns of reasoning could be used legitimately in certain cultural-institutional contexts and not in certain others. This would apply in particular to patterns used in legal interpretation. In fact, in different legal systems different argument schemes-such as appeals to ordinary language meaning, to legislative intention, to preparatory work (drafting history) or to teleology - are used to different extents to support interpretive claims. If argument schemes embody appeal to rationality, how is it possible that their use is so parochial?

Our approach to address such issues was based on two main considerations. First, we affirmed that argument schemes themselves could be justified through arguments. 
In particular, the use of argument schemes can be given a pragmatic justification, namely, a justification based on teleological reasoning, as instantiated by the scheme for practical reasoning, supplemented by arguments from positive and negative consequences. Thus, the use of an argument scheme in the context of an activity would be justified to the extent that the scheme contributes to the cognitive or practical purposes of that activity. Second, we considered that the pragmatic utility, and consequently the justification, of a scheme may depend on the shared acceptance of the scheme. The use of a scheme-such as appeal to ordinary language or to preparatory works in legal interpretation-is justified by the very fact that this scheme promotes engagement and persuasion, or at least acquiescence, and this depends on the existence, in the given context, of a shared disposition to use that scheme.

\subsection{Legal interpretation as argumentation}

The interaction we had in Florence led us to one further project, that was to continue in the following years, namely, an argument-based analysis of legal interpretation. We focused on the classifications of arguments in legal interpretation that had been proposed by the legal theorists, such as Tarello (1980) and MacCormick and Summers (1991). It seemed to us that such jurisprudential analyses provided rich insights into legal discourse, but that additional understanding could be gained by linking them on the one hand to argumentation theory and on the other hand to AI and Law research. Thus, we decided to consider the extent to which interpretive discourse as classified and analysed by legal theorists could be mapped into the argument schemes identified by argumentation theorists such as Doug and his associates (Walton et al. 2008). Moreover, we wanted to provide a structured and possibly computational representations of such arguments. Fabrizio Macagno, who had already extensively cooperated with Doug (see Walton et al. 2008), joined us in this project. A number of contributions were subsequently developed, where we merged the analysis of legal interpretation though argumentation theory and pragmatics, with the modelling of interpretative reasoning through systems for defeasible argumentation, relying in particular on Carneades and ASPIC ${ }^{+}$(Macagno et al. 2014, 2018; Sartor et al. 2014; Walton et al. 2016, 2018). On the one hand we showed that arguments used in legal interpretation could indeed be classified and analysed as instances of the kinds of argument that had been studied in argumentation research. On the other hand, we showed that such arguments could be captured through defeasible conditionals, together with the presuppositions/presumptions concerning their use, and possible attacks against them (critical questions/exceptions). Thus it was possible to model interpretive debates through defeasible argumentation, to capture the dialectical interactions of competing interpretive proposals and attacks against them, as well as the transition from the interpretation of legal provisions to their application to derive substantive conclusions.

The development of this research lead to my final project with Doug, namely, to the idea of preparing a book on argumentation in legal interpretation. The book, co-authored by Doug, Fabrizio Macagno, and myself, entitled The pragmatic and argumentative structure of statutory interpretation, had been completed just before 
Fig. 2 Perspectives on argumentation
Theories and models

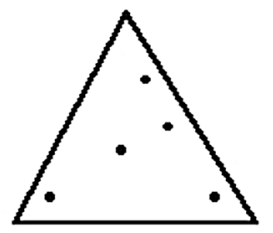

Machines and programs

Doug' s sudden departure from us. It is hopefully going to be published within the current year (2020). The book aims at providing an account of legal interpretation that combines and integrates five different disciplines, each giving a different perspective on legal argumentation: argumentation theory, legal theory, pragmatics, dialectics, and AI and Law. The core of the book is constituted indeed by Doug's approach to argumentation, as contextualised to interpretive debates. After providing an introduction to legal interpretations, argument schemes for statutory interpretations are defined and consistently applied to multiple legal and paralegal examples. Their use is connected to the pragmatics of legal language and legal interactions. Interpretive arguments - such as linguistic, teleological, a contrario, and analogical arguments-are modelled as defeasible modus ponens inferences, subject to challenges and attacks. The book has two main goals, a theoretical one and a practical one. The theoretical goal consists in linking legal argument to general argumentation, i.e., in showing how the complexity of interpretive canons and reasoning can captured by using the instruments that we already use to model everyday conversation. The practical goal consists in furnishing tools to aid with the interpretation of statutory texts, in particular by explicating and visualising, through argument maps, the whole network of competing arguments concerning an interpretive issue.

\section{Bart Verheij: connecting formal, computational and real-life argumentation}

My first encounter with Doug Walton was when he gave one of the invited lectures at the International Conference on Formal and Applied Practical Reasoning (FAPR 1996) that took place in Bonn. I was then near the end of my Ph.D. research and had been struggling with the breadth of perspectives that was helpful and necessary for the study of argumentation in the law (Fig. 2, taken from my report of that conference $^{16}$ ). One is the perspective of theories and models emphasising the formal conceptualization of argumentation, as for instance studied in philosophical logic. A second is the perspective of minds and humans emphasising how argumentation occurs naturally in everyday and professional domains, as for instance studied in the cognitive sciences. And a third and final is the perspective of machines and programs emphasising a computational perspective on how argumentation occurs.

16 https://www.ai.rug.nl/ verheij/publications/fapr96report/, written for Ron Loui. 
The conference was a relief, as there a community was gathering where seemingly everyone was interested in the study of argumentation as an enterprise in between all these perspectives. And Doug was a central member of that community. Until then I had known him only from some of the books I had been borrowing from the university library. I knew his Fallacies co-written with his Ph.D. supervisor John Woods (who survives Doug), and I knew his Informal Logic (Walton 1989). Already these books (just two of already then many) suggested how prolific he was as an author, and how broad his contributions to the study of argumentation.

In his lecture, Doug emphasised the need for the development of an 'applied logic', acknowledging the pragmatic, goal-driven side of reasoning and argumentation. He also spoke of software as a critical thinking tool, a topic at the heart of the computational dialectics workshop organised by Tom Gordon and Gerhard Brewka at that conference, which I also attended.

To me all this felt very fresh, relevant, important. Doug had at that time already written some 20 books on these and related topics.

A second episode of Doug's influence on me as a researcher is a workshop organized by Chris Reed and Tim Norman in Bonskeid House, originally a Scottish mansion, but by then converted to a youth hostel. In that week, a group of some twenty researchers gathered with the goal to produce a book on what Chris and Tim referred to as 'argumentation machines'. The book appeared 4 years later (Reed and Norman 2003) and contains a roadmap of research in argument in computation (by Chris and Tim). Doug coauthored a chapter on argument and multi-agent systems.

The intensity of the event played a role in setting the agenda and building the community for the computational argumentation community, to which Doug contributed from the start: he co-wrote two papers at the first of the biennial Computational Models of Argument conference series (COMMA 2006, Liverpool) (Gordon and Walton 2006a, b, both with Tom Gordon) and wrote a paper for the first issue of the Argument and Computation journal (Walton 2010). Just before he died Doug had finalized a paper for that same journal. It appeared posthumously as Walton (2019).

During the workshop in Bonskeid House, Doug discussed argumentation schemes and their critical questions as catalogued by him in his 1996 book (Walton 1996), later adapted and expanded with Chris Reed and Fabrizio Macagno (Walton et al. 2008). At that time, I had just developed the DefLog formalism (Verheij $2003 \mathrm{~b}$ ), and in that week in Scotland became aware of the fact that argumentation schemes could be given a formal semantics in such an argumentation formalism, with critical questions corresponding to points of attack (Verheij 2001b, 2003c). The perspective became the basis of my work on argument diagramming and evaluation software (Verheij 2003a, 2005, 2007), balancing real life relevance and compliance with Dung (1995). Now that I write this text, that work was clearly an answer to what Doug had been calling for at the 1996 Bonn conference mentioned earlier. Meanwhile Doug was developing his own answer to that call (e.g. Rowe et al. 2006; Gordon and Walton 2006b). 
Doug's ideas on argumentation schemes also helped me with addressing the puzzle of how to connect formal and applied logic. As a mathematician working (then) in a law school, I had been thinking hard about the relation between (on the one hand) the formal rules of inference as they appear in mathematical logic and (on the other hand) the reasoning patterns in law as Jaap Hage and I had been modeling them in Reason-Based Logic (Hage and Verheij 1994). For Jaap, Reason-Based Logic was an approximation of a natural logic, optimizing relevance for law. Our discussions led me to write about whether a 'logic of law' could exist (Verheij 2001c). My answer was yes and no at the same time: yes, a logic of law can exist by formally explicating legally relevant reasoning patterns (a bit like in a natural deduction system, but now a 'legal deduction system'), but also no, since such a legal logic can also be reduced to a set of legal assumptions in a more abstract logic. When I heard Doug speak on argumentation schemes in Bonskeid, I understood that, like Reason-Based Logic, argumentation schemes could be thought of as either being part of a contextual, applied logic, or as a set of contextual assumptions in a more abstract logic (Verheij 2003c). In this context, I made a proposal for a scheme 'Modus non excipiens', a variation of the familiar Modus ponens in the context of defeasibility, that ended up in the Argumentation schemes book (Walton et al. 2008, p. 366):

Modus Non Excipiens (Verheij 2001c)

As a rule, if $\mathrm{P}$, then $\mathrm{Q}$.

P.

It is not the case that there is an exception to the rule that if $\mathrm{P}$, then $\mathrm{Q}$.

Therefore, Q.

A third part of my journey with Doug and his ideas occurred when I was asked to review some of his books for the Artificial Intelligence and Law journal, specifically The New Dialectic (Walton 1998b), Ad Hominem Arguments (Walton 1998a) and One-Sided Arguments (Walton 1999). I then discovered that for Doug, at that time, argumentation schemes did not yet have a standardized format (Verheij 2001a). Concretely, in his Ad Hominem Arguments, the following three all count as argumentation schemes (here AH abbreviates 'ad hominem'):

GENERIC AH [p. 249 in Walton (1998a)] $a$ is a bad person.

Therefore, $a$ 's argument $\alpha$ should not be accepted.

GUILT BY ASSOCIATION AH [pp. 256-257 in Walton (1998a)]

$a$ is a member of or is associated with group $\mathrm{G}$, which should be morally condemned.

Therefore, $a$ is a bad person.

Therefore, $a$ 's argument $\alpha$ should not be accepted.

TWO WRONGS AH [pp. 256-257 in Walton (1998a)] 
Proponent Respondent, you have committed some morally blameworthy action (and the specific action is then cited).

Respondent You are just as bad, for you also committed a morally blameworthy action (then cited, generally a different type of action from the one cited by the proponent but comparable in respect of being blameworthy).

Therefore, you are a bad person, and your argument against me should not be accepted as having any worth.

The first is an argumentation scheme in its by now more standardized format: as a kind of semi-formal rule of inference, with a schematic premise and conclusion. The second is more like a semi-formal derivation, consisting of two steps. Now this would be thought of as built from two instances of an argumentation scheme. The third is like a small boilerplate dialogue, here not even using the schemeindicating variables $a$ (for the attacked arguer) and $\alpha$ (for the attacked argument).

One lesson that I learnt from reviewing these books is how seriously Doug took his emphasis on applied logic: all endeavours in applied logic should be relevant for real life argumentation. Real life relevance always comes first, and only then careful systematization. In formal logic, things often stand the other way around.

The reviewing effort strengthened my perspective on formalizing argumentation schemes. Where first I mostly emphasised the connection between critical questions and argument attack, and the added value of formal evaluation (Verheij 2001b), I now more clearly saw how cataloguing argumentation schemes could be approached as a kind of knowledge engineering enterprise (Verheij 2003c). Each scheme should follow a standard format and consist of lists of premises, conclusions, exceptions and conditions of relevance. As a result of this four-element format, critical questions could also be divided into four kinds: questions about a premise, about a conclusion, about an exception [that I took as blocking the connection between premises and conclusion, following Pollock's idea of undercutting defeat (Pollock 1995)] and about a condition of relevance. These ideas were clearly hanging in the air, as several researchers (including Doug himself) were developing a similar perspective on argumentation schemes in those days.

Floris Bex and I applied this knowledge engineering method towards argumentation schemes when we modeled theoretical approaches to evidential reasoning in terms of argumentation schemes and their critical questions: first, we modeled the anchored narratives theory (Wagenaar et al. 1993), that provides a normative perspective on evidential reasoning in terms of good quality, well-supported scenarios explaining the evidence (Verheij and Bex 2009); then the hybrid theory of evidential reasoning (Bex 2011), that shows how evidential reasoning with arguments and with scenarios go together (Bex and Verheij 2012). Doug himself also continued to have an interest in evidential reasoning and argumentation (e.g. Walton 2016).

When I try to summarize Doug's influence on me, my thinking and my life, Doug showed that: 
1. An applied version of logic can be pursued in terms of argumentation schemes, and gives an all-encompassing perspective on argumentation relevant for all aspects of life;

2. The critical questions that come with argumentation schemes directly suggest possible points of attack of arguments, thereby providing the means to both evaluate arguments and produce a debate;

3. Real life examples and case studies are a necessary and concrete approach to lowering the risk of sterile theorizing without sufficient real life relevance;

4. A mix of formal and non-formal methods can provide a semi-formal middle ground counterbalancing mathematical strictness, a bit like in AI's knowledge representation;

5. An inclusive, welcoming and curious attitude towards researchers and their research is the best way to support the development of ideas and make progress.

The last time I saw Doug in person (as always accompanied by his wife Karen) was in my university's town when he was attending the most recent edition of the European Conference on Argumentation (ECA 2019, Groningen). It has always been a pleasure and an inspiration to follow Doug and his work, and I keep good memories of our encounters, in writing and at academic events.

\section{Concluding remarks}

In this paper we have, as a group of friends and colleagues, described how Doug's work influenced us and the field of AI and Law. Although we have built on the same work, we have often taken it in different directions, which is a testimony to the richness of the ideas. What is remarkable is that Doug has worked with us in taking it in these different directions, which reflects his lack of dogmatism, his generosity as a collaborator, and his intellectual curiosity. The AI and Law community was fortunate that Doug became an active participant in its work, and we, like many others, will miss both his ideas, and him as a person.

Open Access This article is licensed under a Creative Commons Attribution 4.0 International License, which permits use, sharing, adaptation, distribution and reproduction in any medium or format, as long as you give appropriate credit to the original author(s) and the source, provide a link to the Creative Commons licence, and indicate if changes were made. The images or other third party material in this article are included in the article's Creative Commons licence, unless indicated otherwise in a credit line to the material. If material is not included in the article's Creative Commons licence and your intended use is not permitted by statutory regulation or exceeds the permitted use, you will need to obtain permission directly from the copyright holder. To view a copy of this licence, visit http://creativecommons.org/licen ses/by/4.0/.

\section{References}

Aleven V (1997) Teaching case-based argumentation through a model and examples. Ph.D. thesis, University of Pittsburgh 
Atkinson K (2005) What should we do? Ph.D. thesis, University of Liverpool

Atkinson K (2012) Introduction to special issue on modelling Popov v Hayashi. Artif Intell Law 20(1):1-14

Atkinson K, Bench-Capon T (2007) Practical reasoning as presumptive argumentation using action based alternating transition systems. Artif Intell 171(10-15):855-874

Atkinson K, Bench-Capon T (2014) Taking the long view: looking ahead in practical reasoning. In: Proceddings of the Fifth International Conference on Computational Models of Argument (COMMA 2014), pp 109-120

Atkinson K, Bench-Capon T (2018) Taking account of the actions of others in value-based reasoning. Artif Intell 254:1-20

Atkinson K, Bench-Capon T, McBurney P (2004) Justifying practical reasoning. In: Proceedings of the fourth international workshop on computational models of natural argument (CMNA 2004), pp 87-90

Atkinson K, Bench-Capon T, McBurney P (2006) Parmenides: facilitating deliberation in democracies. Artif Intell Law 14(4):261-275

Atkinson K, Bench-Capon TJM, McBurney P (2006) Computational representation of practical argument. Synthese 152(2):157-206

Atkinson K, Bench-Capon T, Prakken H, Wyner A (2013) Argumentation schemes for reasoning about factors with dimensions. Proc JURIX 2013:39-48

Atkinson K, Bench-Capon T, Walton D (2013) Distinctive features of persuasion and deliberation dialogues. Argument Comput 4(2):105-127

Barbuceanu M, Fox MS (1995) Cool: a language for describing coordination in multi agent systems. In: Proceedings of the first international conference on multi-agent systems, pp 17-24

Bench-Capon T (1998) Specification and implementation of Toulmin dialogue game. Proc JURIX 1998:5-20

Bench-Capon T (1998) Specifying the interaction between information sources. In: Proceedings of the ninth international conference on database and expert systems applications. Springer, pp 425-434

Bench-Capon T (2003) Persuasion in practical argument using value-based argumentation frameworks. J Log Comput 13(3):429-448

Bench-Capon T (2012) The long and winding road: forty years of argumentation. In: Proceedings of the fourth international conference on computational models of argument, pp 3-10

Bench-Capon T (2012) Representing Popov v Hayashi with dimensions and factors. Artif Intell Law 20(1):15-35

Bench-Capon T (2017) HYPO's legacy: introduction to the virtual special issue. Artif Intell Law 25(2):205-250

Bench-Capon T, Atkinson K (2010) Argumentation schemes: from informal logic to computational models. In: Reed C, Tindale C (eds) Dialectics, dialogue and argumentation: an examination of Douglas Walton's theories of reasoning and argument. College Publications, London, pp 103-114

Bench-Capon T, Sartor G (2003) A model of legal reasoning with cases incorporating theories and values. Artif Intell 150(1-2):97-143

Bench-Capon T, Sergot M (1988) Towards a rule-based representation of open texture in law. In: Walter C (ed) Computer power and legal language. Quorum Books, New York, pp 38-61

Bench-Capon T, Lowes D, McEnery A (1991) Argument-based explanation of logic programs. KnowlBased Syst 4(3):177-183

Bench-Capon T, Coenen F, Orton P (1993) Argument-based explanation of the British Nationality Act as a logic program. Inf Commun Technol Law 2(1):53-66

Bench-Capon T, Prakken H, Visser W (2011) Argument schemes for two-phase democratic deliberation. In: Proceedings of the thirteenth international conference on artificial intelligence and law. ACM Press, New York, pp 21-30

Bench-Capon T, Atkinson K, McBurney P (2012) Using argumentation to model agent decision making in economic experiments. J Auton Agents Multi Agent Syst 25(1):183-208

Bench-Capon T, Prakken H, Wyner A, Atkinson K (2013) Argument schemes for reasoning with legal cases using values. In: Proceedings of the fourteenth international conference on artificial intelligence and law, pp 13-22

Bench-Capon T, Atkinson K, Wyner A (2015) Using argumentation to structure e-participation in policy making. In: Transactions on large-scale data-and knowledge-centered systems XVIII. Springer, pp $1-29$

Bex F (2011) Arguments, stories and criminal evidence: a formal hybrid theory. Springer, Berlin 
Bex F, Verheij B (2012) Solving a murder case by asking critical questions: an approach to fact-finding in terms of argumentation and story schemes. Argumentation 26:325-353

Bex F, Walton D (2010) Burdens and standards of proof for inference to the best explanation. In: Winkels R (ed) Legal knowledge and information systems. JURIX 2010: the 23rd annual conference. Frontiers in artificial intelligence and applications, vol 223. IOS Press, Amsterdam, pp 37-46

Bex F, Walton D (2012) Burdens and standards of proof for inference to the best explanation: three case studies. Law Probab Risk 11(2-3):113-133

Bex F, Walton D (2016) Combining explanation and argumentation in dialogue. Argument Comput $7(1): 55-68$

Bex F, Walton D (2019) Taking the dialectical stance in reasoning with evidence and proof. Int J Evid Proof 23(1-2):90-99

Bex F, Prakken H, Reed C, Walton D (2003) Towards a formal account of reasoning about evidence: argumentation schemes and generalisations. Artif Intell Law 12:125-165

Bex F, Atkinson K, Bench-Capon T (2014) Arguments as a new perspective on character motive in stories. Literary Linguist Comput 29(4):467-487

Black E, Atkinson K (2009) Dialogues that account for different perspectives in collaborative argumentation. In: Sierra C, Castelfranchi C, Decker KS, Sichman JS (eds) 8th international joint conference on autonomous agents and multiagent systems (AAMAS 2009), vol 2. IFAAMAS, Budapest, Hungary, pp 867-874

Black E, Hunter A (2009) An inquiry dialogue system. Auton Agents Multi-Agent Syst 19(2):173-209

Bobrow D (ed) (1980) Artificial intelligence, vol 13. Special issue on non-monotonic logic

Bongiovanni G, Postema G, Rotolo A, Sartor G, Valentini C, Walton D (2018) Handbook of legal reasoning and argumentation. Springer, Berlin

Cartwright D, Atkinson K (2009) Using computational argumentation to support e-participation. IEEE Intell Syst 24(5):42-52

Dennett DC (1989) The intentional stance. MIT Press, Cambridge

Dung PM (1995) On the acceptability of arguments and its fundamental role in nonmonotonic reasoning, logic programming and n-person games. Artif Intell 77(2):321-357

Dunne PE, Doutre S, Bench-Capon T (2005) Discovering inconsistency through examination dialogues. In: Proceedings of the 19th international joint conference on artificial intelligence, pp 1680-1681

Finin T, Fritzson R, McKay D, McEntire R (1994) KQML as an agent communication language. In: Proceedings of the third international conference on information and knowledge management, $\mathrm{pp}$ $456-463$

Frühwirth T (2009) Constraint handling rules. Cambridge University Press, Cambridge

Gabbay DM, Ohlbach HJ (eds) (1996) Practical reasoning: proceedings of the first international conference on formal and applied practical reasoning. Lecture notes in computer science, vol 1085. Springer

Gardner A (1987) An artificial intelligence approach to legal reasoning. MIT Press, Cambridge

Gordon TF (1994) The pleadings game: an exercise in computational dialectics. Artif Intell Law 2:239-292

Gordon TF (1995) The pleadings game; an artificial intelligence model of procedural justice. Kluwer Academic Publishers, Dordrecht, Boston

Gordon TF (2005) A computational model of argument for legal reasoning support systems. In: Dunne PE, Bench-Capon T (eds) Argumentation in artificial intelligence and law. IAAIL workshop series. Wolf Legal Publishers, Nijmegen, The Netherlands, pp 53-64

Gordon TF (2007) 20 years of ICAIL: reflections on the field of AI and law. In: International conference on artificial intelligence and law (ICAIL 2007). Stanford University. Keynote address

Gordon TF (2018) Defining argument weighing functions. IfCoLog J Log Appl 5(3):747-773

Gordon TF, Karacapilidis N (1997) The Zeno argumentation framework. In: Proceedings of the sixth international conference on artificial intelligence and law. ACM Press, Melbourne, Australia, pp 10-18

Gordon TF, Walton D (2006) Pierson vs. Post revisited-a reconstruction using the Carneades argumentation framework. In: Dunne PE, Bench-Capon TJ (eds) Proceedings of the first international conference on computational models of argument (COMMA 06). IOS Press, Liverpool, pp 208-222

Gordon TF, Walton D (2006) The Carneades argumentation framework-using presumptions and exceptions to model critical questions. In: Dunne PE, Bench-Capon TJM (eds) Computational models of argument. Proceedings of COMMA 2006. IOS Press, Amsterdam, pp 195-207 
Gordon TF, Walton D (2009) Legal reasoning with argumentation schemes. In: Hafner CD (ed) 12th international conference on artificial intelligence and law (ICAIL 2009). ACM Press, New York, NY, USA, pp 137-146

Gordon TF, Walton D (2009) Proof burdens and standards. In: Rahwan I, Simari G (eds) Argumentation in artificial intelligence. Springer, Berlin, pp 239-260

Gordon TF, Walton D (2012) A Carneades reconstruction of Popov v Hayashi. Artif Intell Law 20(1):37-56

Gordon TF, Walton D (2016) Formalizing balancing arguments. In: Proceeding of the 2016 conference on computational models of argument (COMMA 2016). IOS Press, pp 327-338

Gordon TF, Prakken H, Walton D (2007) The Carneades model of argument and burden of proof. Artif Intell 171(10-11):875-896

Gordon TF, Friederich H, Walton D (2017) Representing argumentation schemes with constraint handling rules (CHR). Argument Comput 9(2):91-119

Greenwood K, Bench-Capon T, McBurney P (2003) Towards a computational account of persuasion in law. In: Zeleznikow J, Sartor G (eds) Proceedings of the 9th international conference on artificial intelligence and law, ICAIL 2003. ACM, Edinburgh, Scotland, UK, pp 22-31

Hage JC, Verheij B (1994) Reason-based logic: a logic for reasoning with rules and reasons. Law Comput Artif Intell 3(2-3):171-209

Hage J, Leenes R, Lodder A (1993) Hard cases: a procedural approach. Artif Intell Law 2:113-166

Hamblin CL (1970) Fallacies. Methuen, London

Hastings AC (1963) A reformulation of the modes of reasoning in argumentation. Ph.D. thesis, Northwestern University, Evanston, Illinois

Hurley P (2003) Logic: a concise introduction. Wadsworth, Belmont

Huygen P (2002) Use of Bayesian belief networks in legal reasoning. In: 17th BILETA annual conference, Amsterdam, pp 2-14

Josephson JR, Josephson SG (1996) Abductive inference: computation, philosophy, technology. Cambridge University Press, Cambridge

Kadane JB, Schum DA (2011) A probabilistic analysis of the Sacco and Vanzetti evidence, vol 773. Wiley, New York

Kenny AJP (1978) Practical reasoning and rational appetite. In: Raz J (eds) Practical reasoning. Oxford University Press, pp 63-80

Kienpointner M (1992) Alltagslogik: Struktur und Funktion von Argumentationsmustern. FrommanHolzboog, Stuttgart

Kirchev Y, Atkinson K, Bench-Capon T (2019) Demonstrating the distinctions between persuasion and deliberation dialogues. In: Bramer M, Petridis M (eds) Artificial intelligence XXXVI-39th SGAI international conference on artificial intelligence. Lecture notes in computer science, vol 11927. Springer, pp 93-106

Kurtuldu B (2019) Douglas Walton'ın argüman biçimleri yaklaşımı. Felsefe Arkivi 51:161-178

Labrou Y, Finin T (1994) A semantics approach for KQML - a general purpose communication language for software agents. In: Proceedings of the third international conference on information and knowledge management, pp 447-455

Lodder A, Herczog A (1995) A dialogical framework for modeling legal reasoning. In: Proceedings of the fifth international conference on artificial intelligence and law. ACM Press, New York, pp 146-155

Loui R (1987) Defeat among arguments: a system of defeasible inference. Comput Intell 2:100-106

Lucas P (1997) Symbolic diagnosis and its formalisation. Knowl Eng Rev 12(2):109-146

Lutomski LS (1989) The design of an attorney's statistical consultant. In: Proceedings of the 2nd international conference on artificial intelligence and law. ACM, pp 224-233

Macagno F, Walton D, Sartor G (2014) Argumentation schemes for statutory interpretation. In: Araszkiewicz M (ed) International conference on alternative methods of argumentation in law, Brno, pp $61-75$

Macagno F, Walton D, Reed C (2017) Argumentation schemes. History, classifications, and computational applications. J Appl Log IfCoLoG J Log Appl 4(8):2493-2556

Macagno F, Walton D, Sartor G (2018) Pragmatic maxims and presumptions in legal interpretation. Law Philos 37:69-115

MacCormick DN, Summers RS (1991) Interpretation and justification. In: MacCormick DN, Summers RS (eds) Interpreting statutes: a comparative study. Darthmouth, Hanover, pp 511-44

Mackenzie JD (1979) Question-begging in non-cumulative systems. J Philos Log 8:117-133 
Marshall CC (1989) Representing the structure of a legal argument. In: Proceedings of the 2nd international conference on artificial intelligence and law. ACM, pp 121-127

Miller T (2019) Explanation in artificial intelligence: insights from the social sciences. Artif Intell 267:1-38

Modgil S, Prakken H (2014) The ASPIC ${ }^{+}$framework for structured argumentation: a tutorial. Argument Comput 5:31-62

Modgil S, Prakken H (2018) Abstract rule-based argumentation. In: Baroni P, Gabbay D, Giacomin M, van der Torre L (eds) Handbook of formal argumentation, vol 1. College Publications, London, pp 286-361

Pennington N, Hastie R (1993) The story model for juror decision making. Cambridge University Press, Cambridge

Perelman C, Olbrechts-Tyteca L (1969) The new rhetoric: a treatise on argumentation, trans. University of Notre Dame Press, Notre Dame

Pollock J (1987) Defeasible reasoning. Cogn Sci 11:481-518

Pollock J (1994) Justification and defeat. Artif Intell 67:377-408

Pollock J (1995) Cognitive carpentry. A blueprint for how to build a person. MIT Press, Cambridge

Poole D (1985) On the comparison of theories: preferring the most specific explanation. In: Proceedings of the 9th international joint conference on artificial intelligence, pp 144-147

Prakken H (1991) A tool in modelling disagreement in law: preferring the most specific argument. In: Proceedings of the third international conference on artificial intelligence and law. ACM Press, New York, pp 165-174

Prakken H (2005) Coherence and flexibility in dialogue games for argumentation. J Log Comput 15:1009-1040

Prakken H (2005) A study of accrual of arguments, with applications to evidential reasoning. In: Proceedings of the tenth international conference on artificial intelligence and law. ACM Press, New York, pp 85-94

Prakken H (2006) Formal systems for persuasion dialogue. Knowl Eng Rev 21(2):163-188

Prakken H (2008) A formal model of adjudication dialogues. Artif Intell Law 16(3):305-328

Prakken H (2010) An abstract framework for argumentation with structured arguments. Argument Comput 1:93-124

Prakken H (2010) On the nature of argument schemes. In: Reed C, Tindale C (eds) Dialectics, dialogue and argumentation. An examination of Douglas Walton's theories of reasoning and argument. College Publications, London, pp 167-185

Prakken H (2015) Formalising debates about law-making proposals as practical reasoning. In: Araszkiewicz M, Płeszka K (eds) Logic in the theory and practice of lawmaking. Springer, Berlin, pp $301-321$

Prakken H (2019) Modelling accrual of arguments in $\mathrm{ASPIC}^{+}$. In: Proceedings of the seventeenth international conference on artificial intelligence and law, pp 103-112

Prakken H, Sartor G (1996) A dialectical model of assessing conflicting arguments in legal reasoning. Artif Intell Law 4:331-368

Prakken H, Sartor G (1997) Argument-based extended logic programming with defeasible priorities. J Appl Non-class Log 7:25-75

Prakken H, Sartor G (2007) Formalising arguments about the burden of persuasion. In: Proceedings of the eleventh international conference on artificial intelligence and law. ACM Press, New York, pp 97-106

Prakken H, Sartor G (2009) A logical analysis of burdens of proof. In: Kaptein H, Prakken H, Verheij B (eds) Legal evidence and proof: statistics, stories, logic. Ashgate Publishing, Farnham, pp 223-253

Prakken H, Reed C, Walton D (2004) Argumentation schemes and burden of proof. In: Proceedings of the ECAI-2004 workshop on computational models of natural argument, pp 81-86

Prakken H, Reed C, Walton D (2005) Dialogues about the burden of proof. In: Proceedings of the tenth international conference on artificial intelligence and law. ACM Press, New York, pp 115-124

Prakken H, Wyner A, Bench-Capon T, Atkinson K (2015) A formalization of argumentation schemes for legal case-based reasoning in $\mathrm{ASPIC}^{+}$. J Log Comput 25(5):1141-1166

Reed C, Norman T (eds) (2003) Argumentation machines. New frontiers in argument and computation, vol 9. Argumentation library. Kluwer Academic Publishers, Boston, Dordrecht, London

Reed C, Rowe G (2004) Araucaria: software for argument analysis, diagramming and representation. Int J AI Tools 13(4):961-980 
Rissland EL, Ashley KD (1987) A case-based system for trade secrets law. In: Proceedings of the first international conference on artificial intelligence and law. ACM Press, New York, pp 60-66

Rowe G, Macagno F, Reed C, Walton D (2006) Araucaria as a tool for diagramming arguments in teaching and studying philosophy. Teach Philos 29(2):111-124

Sartor G, Walton D, Macagno F, Rotolo A (2014) Argumentation schemes for statutory interpretation: a logical analysis. In: Hoekstra R (ed) Legal knowledge and information system: Jurix-2014. IOS, pp 11-20

Schank RC, Abelson RP (1977) Scripts, plans, goals, and understanding: an inquiry into human knowledge structures. Psychology Press, London

Searle JR (1969) Speech acts: an essay in the philosophy of language, vol 626. Cambridge University Press, Cambridge

Shortliffe EH, Buchanan BG (1985) Rule-based expert systems: the MYCIN experiments of the Stanford heuristic programming project. Addison-Wesley Publishing Company, Boston

Singh MP (2000) A social semantics for agent communication languages. In: Dignum F, Greaves M (eds) Issues in agent communication. Springer, Berlin, pp 31-45

Slomkowski P (1997) Aristotle's topics, vol 74. Brill Academic Publishers, Leiden

Smith IA, Cohen PR (1996) Toward a semantics for an agent communications language based on speechacts. In: AAAI/IAAI, vol 1. Citeseer, pp 24-31

Sycara KP (1998) Multiagent systems: special issue on agents. AI Mag 19(2):79-92

Tarello G (1980) L'interpretazione della legge. Giuffrè, Milano

Tolchinsky P, Modgil S, Atkinson K, McBurney P, Cortés U (2012) Deliberation dialogues for reasoning about safety critical actions. Auton Agents Multi Agent Syst 25(2):209-259

Toni F (2014) A tutorial on assumption-based argumentation. Argument Comput 5(1):89-117

Toulmin SE (1958) The uses of argument. Cambridge University Press, Cambridge

van der Hoek W, Roberts M, Wooldridge MJ (2007) Social laws in alternating time: effectiveness, feasibility, and synthesis. Synthese 156(1):1-19

van Eemeren FH, Grootendorst R (1992) Argumentation, communication and fallacies. Lawrence Erlbaum Associates, Mahwah

van Eemeren FH, Grootendorst R (2016) Argumentation, communication, and fallacies: a pragma-dialectical perspective. Routledge, London

Verheij B (2001) Book review of D. Walton's 'the new dialectic', 'ad hominem arguments' and 'onesided arguments'. Artif Intell Law 9:305-313

Verheij B (2001) Legal decision making as dialectical theory construction with argumentation schemes. In: The 8th international conference on artificial intelligence and law. Proceedings of the conference. ACM, New York, NY, pp 225-226

Verheij B (2001) Logic, context and valid inference. Or: can there be a logic of law? In: van den Herik HJ, Moens MF, Bing J, van Buggenhout B, Zeleznikow J, Grütters CAFM (eds) Legal knowledge based systems. JURIX 1999: the twelfth conference. Kluwer Academic Publishers, Dordrecht, pp 55-84

Verheij B (2003) Artificial argument assistants for defeasible argumentation. Artif Intell 150(1-2):291-324

Verheij B (2003) DefLog: on the logical interpretation of prima facie justified assumptions. J Log Comput 13(3):319-346

Verheij B (2003) Dialectical argumentation with argumentation schemes: an approach to legal logic. Artif Intell Law 11(2-3):167-195

Verheij B (2005) Virtual arguments. On the design of argument assistants for lawyers and other arguers. T.M.C. Asser Press, The Hague

Verheij B (2007) Argumentation support software: boxes-and-arrows and beyond. Law Probab Risk 6:187-208

Verheij B, Bex F (2009) Accepting the truth of a story about the facts of a criminal case. In: Kaptein H, Prakken H, Verheij B (eds) Legal evidence and proof: statistics, stories, logic. Ashgate, Farnham, pp 161-193

Viehweg T (1993) Topics and law: a contribution to basic research in law. Lang, Bern

Vreeswijk G (1993) Studies in defeasible argumentation. Doctoral dissertation, Free University Amsterdam

Vreeswijk G (1997) Abstract argumentation systems. Artif Intell 90:225-279

Wagenaar WA, van Koppen PJ, Crombag HFM (1993) Anchored narratives. The psychology of criminal evidence. Harvester Wheatsheaf, London 
Walton D (1989) Informal logic: a handbook for critical argument. Cambridge University Press, Cambridge

Walton D (1996) Argumentation schemes for presumptive reasoning. Lawrence Erlbaum Associates, Mahwah

Walton D (1998) Ad hominem arguments. The University of Alabama Press, Tuscalooso

Walton D (1998) The new dialectic: conversational contexts of argument. University of Toronto Press, Toronto, Buffalo

Walton D (1999) One-sided arguments. A dialectical analysis of bias. State University of New York Press, Albany

Walton D (2002) Legal argumentation and evidence. Pennsylvania State University Press, University Park Walton D (2005) Argumentation methods for artificial intelligence in law. Springer, Berlin

Walton D (2006) Character evidence - an abductive theory. Springer, Berlin

Walton D (2006) Fundamentals of critical argumentation. Cambridge University Press, Cambridge

Walton D (2007) Dialog theory for critical argumentation. John Benjamins Publishing Company, Amsterdam

Walton D (2008) Witness Testimony evidence-argumentation, artificial intelligence and law. Cambridge University Press, Cambridge

Walton D (2010) A dialogue model of belief. Argument Comput 1(1):23-46

Walton D (2014) Burden of proof, presumption and argumentation. Cambridge University Press, Cambridge

Walton D (2016) Argument evaluation and evidence. Springer, Berlin

Walton D (2019) Using argumentation schemes to find motives and intentions of a rational agent. Argument Comput 10(3):233-275

Walton D, Godden D (2005) The nature of critical questions in argumentation schemes. In: Hitchcock D (ed) The uses of argument. McMaster University, Hamilton, pp 476-484

Walton D, Gordon TF (2005) Critical questions in computational models of legal argument. In: Dunne PE, Bench-Capon T (eds) Argumentation in artificial intelligence and law. IAAIL workshop series. Wolf Legal Publishers, Nijmegen, The Netherlands, pp 103-111

Walton D, Gordon TF (2012) The Carneades model of argument invention. Pragmat Cognit 20(1):1-31

Walton D, Gordon TF (2015) Formalizing informal logic. Informal Log 35(4):508-538

Walton D, Gordon TF (2017) Argument invention with the Carneades argumentation system. Scr-Ed 14(2):168-207

Walton D, Gordon TF (2018) How computational tools can help rhetoric and informal logic with argument invention. Argumentation 33:269-295

Walton D, Krabbe E (1995) Commitment in dialogue: basic concepts of interpersonal reasoning. SUNY Press, Albany

Walton D, Reed C, Macagno F (2008) Argumentation schemes. Cambridge University Press, Cambridge

Walton D, Tindale C, Gordon TF (2014) Applying recent argumentation methods to some ancient examples of plausible reasoning. Argumentation 28(1):85-119

Walton D, Sartor G, Macagno F (2016) An argumentation framework for contested cases of statutory interpretation. Artif Intell Law 24:51-91

Walton D, Sartor G, Macagno F (2018) Statutory interpretation as argumentation. In: Bongiovanni G, Postema G, Rotolo A, Sartor G, Valentini C, Walton D (eds) Handbook of legal reasoning and argumentation. Springer, Berlin, pp 519-560

Wardeh M (2010) Arguing from experience: persuasive dialogue based on association rules. Ph.D. thesis, University of Liverpool

Wardeh M, Bench-Capon T, Coenen F (2007) Padua protocol: strategies and tactics. In: European conference on symbolic and quantitative approaches to reasoning and uncertainty. Springer, pp 465-476

Wardeh M, Bench-Capon T, Coenen F (2009) Padua: a protocol for argumentation dialogue using association rules. Artif Intell Law 17(3):183-215

Wigmore JH (1937) The science of judicial proof, as given by logic, psychology, and general experience, and illustrated in judicial trials. Little, Brown, Boston

Woods J, Walton D (1978) Arresting circles in formal dialogues. J Philos Log 7:73-90

Wooldridge M, Parsons S (2000) Issues in the design of negotiation protocols for logic-based agent communication languages. In: International workshop on agent-mediated electronic commerce. Springer, pp 70-83

Wyner A, Bench-Capon T (2007) Argument schemes for legal case-based reasoning. In: Proceedings of JURIX 2007. Citeseer, pp 139-149 
Wyner A, Bench-Capon T, Atkinson K (2011) Towards formalising argumentation about legal cases. In: Proceedings of the 13th international conference on artificial intelligence and law, pp 1-10

Wyner A, Wardeh M, Bench-Capon T, Atkinson K (2012) A model-based critique tool for policy deliberation. In: JURIX, pp 167-176

Publisher's Note Springer Nature remains neutral with regard to jurisdictional claims in published maps and institutional affiliations. 